\title{
Why is there more ionosphere in January than in July? The annual asymmetry in the F2-layer
}

\author{
H. Rishbeth ${ }^{1}$ and I. C. F. Müller-Wodarg ${ }^{2}$ \\ ${ }^{1}$ School of Physics and Astronomy, University of Southampton, Southampton SO17 1BJ, UK \\ ${ }^{2}$ Space and Atmospheric Physics Group, Imperial College, London SW7 2BZ, UK
}

Received: 11 May 2006 - Revised: 1 September 2006 - Accepted: 26 October 2006 - Published: 21 December 2006

\begin{abstract}
Adding together the northern and southern hemisphere values for pairs of stations, the combined peak electron density $N m$ F2 is greater in December-January than in June-July. The same applies to the total height-integrated electron content. This "F2-layer annual asymmetry" between northern and southern solstices is typically $30 \%$, and thus greatly exceeds the $7 \%$ asymmetry in ion production due to the annual variation of Sun-Earth distance. Though it was noticed in ionospheric data almost seventy years ago, the asymmetry is still unexplained.

Using ionosonde data and also values derived from the International Reference Ionosphere, we show that the asymmetry exists at noon and at midnight, at all latitudes from equatorial to sub-auroral, and tends to be greater at solar minimum than solar maximum. We find a similar asymmetry in neutral composition in the MSIS model of the thermosphere. Numerical computations with the Coupled ThermosphereIonosphere-Plasmasphere (CTIP) model give a much smaller annual asymmetry in electron density and neutral composition than is observed. Including mesospheric tides in the model makes little difference. After considering possible explanations, which do not account for the asymmetry, we are left with the conclusion that dynamical influences of the lower atmosphere (below about $30 \mathrm{~km}$ ), not included in our computations, are the most likely cause of the asymmetry.
\end{abstract}

Keywords. Ionosphere (Ionosphere-atmosphere interactions; Mid-latitude ionosphere) - Atmospheric composition and structure (Thermosphere-composition and chemistry)

\section{Introduction}

\subsection{Background}

Taken over the world as a whole, the peak electron density $N m \mathrm{~F} 2$ of the ionospheric F2-layer, or the critical frequency $f o \mathrm{~F} 2$, is greater in January than in July. We call this the "annual asymmetry", though it is sometimes called the "annual"

Correspondence to: hr@ phys.soton.ac.uk or "non-seasonal" anomaly in contrast to the better-known "seasonal" or "winter" anomaly often found at mid-latitudes, in which midday $N m \mathrm{~F} 2$ is greater in winter than in summer (it could be called the "solsticial" anomaly). The annual asymmetry can only be separated from the seasonal anomaly by combining data from opposite seasons in the two hemispheres. Indeed, the question might alternatively be stated as "the seasonal anomaly is greater in the northern hemisphere than the southern". Whether that is the whole story, or whether the annual asymmetry has its own distinct physical cause, needs to be investigated. In any case, we must be open to the possibility that the asymmetry is "hemispheric" - a difference between hemispheres rather than between solstices.

An obvious possible cause of the annual asymmetry is the January/July variation of $3.5 \%$ in Sun-Earth distance and the consequent $7 \%$ variation in the flux of ionizing radiation. The puzzle is that the January/July difference in global $N m \mathrm{~F} 2$ is much greater than $7 \%$. The phase of the variation of Sun-Earth distance, however, is our main reason for comparing January and July instead of the actual solstice months December and June. The situation is complicated by the widespread semiannual variation of $N m \mathrm{~F} 2$ (and of other features in upper atmosphere and geomagnetism), of which the maxima occur in April and October and the minima in January and July. We must take account of this semiannual variation, even though it is not our main topic, and choosing January and July as reference months helps us to deal with it. We have no reason to believe that using December and June as reference months, instead of January and July, would affect our conclusions in any significant way.

The annual asymmetry does not have exactly the same amplitude everywhere, so the annual variation in the flux of solar ionizing radiation cannot be the only factor. Yonezawa and Arima (1959) suggested that the asymmetry might be due to interplanetary corpuscular radiation, but had no evidence to support this idea. In a little-known paper, Buonsanto (1986) suggested that the neutral $\mathrm{O} / \mathrm{O}_{2}$ concentration ratio also varies annually, because the varying Sun-Earth distance modulates the radiation that dissociates molecular oxygen.

Published by Copernicus GmbH on behalf of the European Geosciences Union. 
His further idea, which he discussed with one of us (HR) not long before his untimely death in 1999 but never published as far as we know, is that the varying $\mathrm{O} / \mathrm{O}_{2}$ ratio modulates the electron loss coefficient in the F2-layer, thus enhancing the effect of varying Sun-Earth distance. We call this "Buonsanto's hypothesis". Without any such enhancement, and assuming (as generally accepted) that the electron loss rate in the F2-layer is linear in electron density, the annual asymmetry of $N m \mathrm{~F} 2$ should only be $\pm 3.5 \%$ in amplitude, corresponding to the $7 \%$ variation of Sun-Earth distance.

In this paper we review previous work, present new data analysis, and use the Coupled Thermosphere-IonospherePlasmasphere (CTIP) Model to investigate the asymmetry. We discuss a variety of possible causes, such as atmospheric tides or waves or other influences from below.

\subsection{Previous studies of the asymmetry}

The annual asymmetry was first reported by Berkner and Wells (1938) and Seaton and Berkner (1939). The former remarked that "variations in one [hemisphere] are not predicted at the other with the hypotheses that are advanced to explain them". The problem was well stated by Tremellen and Cox (1947), whose paper was probably the first comprehensive published account of radio propagation conditions based on the worldwide data amassed in World War II. Then, as now, the F2-layer stood out from the other ionospheric layers because of its complexity. Tremellen and Cox (1947) referred to annual, seasonal and other variations of the F2-layer, and observed that: "A given geographic and geomagnetic latitude defines in general two points in each hemisphere, and it has been assumed that F2 will behave similarly at all four points, with due regard to season for the change from northern to southern hemisphere. If this were so, the number of ionosphere stations required could be cut to one-quarter, but unfortunately it is not exactly so."

Their words refer to the then topical "longitude effect" in F2-layer parameters, it being realized that longitude variations at a given latitude depend on the geomagnetic field, as was discovered by Japanese radio scientists from wartime observations in the Pacific (Bailey, 1948). Subsequently, Yonezawa and Arima (1959) estimated the annual (non-seasonal) component by averaging data from several ionosonde stations in northern mid-latitudes with corresponding data from southern mid-latitudes. Yonezawa (1971) realized the desirability of pairing individual northern and southern stations according to both geographic and magnetic latitude, and gave comprehensive results based on ionosonde data.

Titheridge and Buonsanto (1983) reported the annual, seasonal and semiannual variations of ionospheric total electron content at two north-south pairs of stations, which we discuss in Sect. 2.6. Su et al. (1998) analysed the annual and seasonal variations of electron density at $600 \mathrm{~km}$ height, measured at low latitudes in 1981-1982 by an impedance probe aboard the Hinotori satellite, and compared the results with calculations by the Sheffield SUPIM model (Sects. 2.5, 3.1).

\subsection{Plan of the paper}

Section 2 of this paper describes the annual asymmetry as given by ionosonde data, and by measurements of total electron content, for north-south pairs of stations. We find that choosing suitable pairs is quite difficult, so we should consider other sources of ionospheric data. Topside sounders provide extensive data on $f o \mathrm{~F} 2$ and thus $N m \mathrm{~F} 2$, which might be useful for future studies. Satellite in-situ measurements at fixed heights are not very useful for studying the behaviour of the F2 peak, though they are useful for the different problem of the annual variation in the plasmasphere (e.g., Richards et al., 2000). The International Reference Ionosphere (IRI, Rawer et al., 1978; Bilitza, 2001 and references therein) is constructed from many data sources and provides a global picture of the ionosphere. As the IRI can be used to estimate $N m \mathrm{~F} 2$ at any location, whether or not a station exists there, in principle one could get better geographic and geomagnetic matches between northern and southern locations, though the IRI has uncertainties of its own. Section 3 considers evidence for an annual asymmetry in the neutral thermosphere, using both the MSIS model and data from the Atmospheric Explorer satellite.

Section 4 presents computational results for station pairs from the CTIP model used by Zou et al. (2000). We investigate the effects of varying Sun-Earth distance and of tides propagated from below the thermosphere. To evaluate Buonsanto's hypothesis (see Sect. 1.1) on the role of oxygen dissociation in the asymmetry, we need to consider F-layer photochemistry, in particular the neutral $\mathrm{O} / \mathrm{O}_{2}$ and $\mathrm{O} / \mathrm{N}_{2}$ concentration ratios, using results from CTIP and the experimentally based MSIS model (Hedin, 1987).

Section 5 discusses the possible effect of waves and tides propagated from lower levels in the atmosphere, which are a possible source of the annual asymmetry, and Sect. 6 asks whether there are annual variations in other ionospheric parameters. Section 7 reviews other conceivable explanations of the F2-layer annual asymmetry. Section 8 discusses and summarizes the position we have reached.

\section{Ionospheric data from pairs of stations}

\subsection{Methods of analysing the annual asymmetry}

There is more than one way of defining the annual asymmetry in $N m \mathrm{~F} 2$. As explained in the Introduction, we adopt January and July as our reference months. Using pairs of stations, we might compare the January/July ratio in the north with the July/January ratio in the south. We prefer to use the ratio of the amplitude of the annual component to the annual mean, which Yonezawa (1971) calls (a/e) and we call the asymmetry index $A I$, because this is the way in which 
the asymmetry is usually discussed in the literature. In the Yonezawa's formulation (his Eq. 1) the phases are such that the semiannual terms vanish in January and July, and the annual term is most positive in January and most negative in July. Yonezawa derived his results by Fourier analysis of the monthly values of $N m \mathrm{~F} 2$ for northern and southern stations though, as a device to fit the data better, he assumed a semiannual modulation of the annual and seasonal terms, which introduces terannual terms.

Let symbols $W, A, S$ and $M$ respectively denote the amplitudes of the winter/summer, annual and semiannual variations and the annual mean of $N m \mathrm{~F} 2$, where $(\mathrm{N})$ and $(\mathrm{S})$ in brackets denote North and South:

$$
\begin{aligned}
& N m \mathrm{~F} 2(\mathrm{~N})_{\text {Jan }}=M+A+W-S \\
& N m \mathrm{~F} 2(\mathrm{~S})_{\text {Jan }}=M+A-W-S \\
& N m \mathrm{~F} 2(\mathrm{~N})_{\text {July }}=M-A-W-S \\
& N m \mathrm{~F} 2(\mathrm{~S})_{\text {July }}=M-A+W-S
\end{aligned}
$$

Adding Eq. (1a) to Eq. (1b) and Eq. (1c) to Eq. (1d), we have

$$
\begin{aligned}
& N m \mathrm{~F} 2(\mathrm{~N}+\mathrm{S})_{\text {Jan }}=2(M+A-S) \\
& N m \mathrm{~F} 2(\mathrm{~N}+\mathrm{S})_{\text {July }}=2(M-A-S)
\end{aligned}
$$

If we ignore $S$ for the moment, we can solve Eqs. (2a) and (2b) for $A$ and $M$, and define the "annual asymmetry index" $A I$ as

$$
A I=(A / M)=\frac{N m \mathrm{~F} 2(\mathrm{~N}+\mathrm{S})_{\mathrm{Jan}}-N m \mathrm{~F} 2(\mathrm{~N}+\mathrm{S})_{\mathrm{July}}}{N m \mathrm{~F} 2(\mathrm{~N}+\mathrm{S})_{\mathrm{Jan}}+N m \mathrm{~F} 2(\mathrm{~N}+\mathrm{S})_{\mathrm{July}}}
$$

Thus $A I$ is positive if the January/July ratio exceeds 1 and negative if it is less than 1 . A January/July ratio of 1.1 corresponds approximately to an asymmetry index $A I=0.05$.

In deriving Eq. (3), we ignored the semiannual component $S$. Being the same in both January and July, this term does not affect the January-July difference in the numerator of Eq.(3); but it does affect the denominator and thus affects the resulting value of AI. According to Yonezawa (1971), the semiannual variation is consistently about $20 \%$ of the annual mean, so we take $S / M=0.2$, and can easily show that this introduces a factor $(1-(S / M))=0.8$ into the right-hand side of Eq. (3). We decided not to make this correction, because of tests in which we derived the asymmetry $A I$ both from Eq. (3) and by Fourier analysis of all twelve months' data. We found that, both for the ionosonde data (Sect. 3.2) and for modelling (Sect. 3.3), the two methods agree better if the factor of 0.8 is omitted. The reason may be that Eqs. $(2 \mathrm{a}-\mathrm{b})$ are oversimplified, and the variation of $N m \mathrm{~F} 2$ is not well fitted just with annual and semiannual sinusoids. In any case, the discrepancies between observational and computed values of $A I$ are such that a $20 \%$ uncertainty is not too important.
Another question to be asked is "Does the annual asymmetry depend more on winter values of $N m \mathrm{~F} 2$ than on summer values?". The "winter contribution" to the asymmetry index is $N m \mathrm{~F} 2(\mathrm{~N})_{\mathrm{Jan}}-N m \mathrm{~F} 2(\mathrm{~S})_{\mathrm{July}}$ and the "summer contribution" is $N m \mathrm{~F} 2(\mathrm{~S})_{\text {Jan }}-N m \mathrm{~F} 2(\mathrm{~N})_{\text {July }}$. To answer this, we consider in Sect. 2.3 the ratio of these contributions, namely

$$
\begin{aligned}
& (W: S)= \\
& \left(N m \mathrm{~F} 2(\mathrm{~N})_{\text {Jan }}-N m \mathrm{~F} 2(\mathrm{~S})_{\text {July }}\right) /\left(N m \mathrm{~F} 2(\mathrm{~S})_{\text {Jan }}-N m \mathrm{~F} 2(\mathrm{~N})_{\text {July }}\right)(4)
\end{aligned}
$$

\subsection{Choosing pairs of stations}

There are several possible ways of investigating the asymmetry. We might compare hemispheric averages of $\mathrm{NmF} 2$, or discrete latitude bands, defined either geographically or geomagnetically. Bearing in mind the words of Tremellen and Cox (1947), quoted earlier, our preferred approach is to define north-south pairs of stations that we match as closely as practicable in both geographic and magnetic latitudes, designated A-Q in Table 1. We give geographic coordinates to the nearest degree, and use the International Geomagnetic Reference Field for epoch 1975 to compute corrected magnetic latitudes at $300 \mathrm{~km}$ height, used only to order the pairs in the table.

The original discovery of the annual asymmetry by Seaton and Berkner (1939) used data from two Carnegie ionosondes, Washington DC and Watheroo, Western Australia, which form quite a good pair. The measurements were made in 1935-1937, with mean annual sunspot number 77 which corresponds to decimetric radio flux $F_{10.7} \approx 130$. Yonezawa (1971) analysed data spanning a wide range of $F_{10.7}$ (mean $\sim 140$ ) from several station pairs. The stations studied by Zou et al. (2000) form three pairs: Slough-Kerguelen, Wallops Island-Hobart and Wakkanai-Port Stanley (referred to as "Zou et al. pairs"), for which we examine monthly mean $N m$ F2 for $F_{10.7} \approx 100$ (years $1961 / 1962 / 1966 / 1973 / 1984$ ) and mean $F_{10.7} \approx 180$ (years 1957-1959/1979-1981/19891990), though not all these years are used for all stations. Later in the paper (Sects. 3.1 and 4.3), we also study four pairs of points, called " $1-4$ ", in the Pacific sector where geomagnetic effects should be minimal. In Sect. 2.4 we consider two "equatorial pairs", a "geographic equatorial" pair Singapore-Talara and "magnetic equatorial" pair Kodaikanal-Huancayo. Section 2.5 considers results for two pairs, Stanford-Auckland and Maui-Rarotonga, for which Titheridge and Buonsanto (1983) analysed total electron content data. For some stations, only daytime $N m \mathrm{~F} 2$ data are useable. All these stations are shown on the map (Fig. 1).

\subsection{Asymmetry in $N m \mathrm{~F} 2$ at pairs of stations}

Table 1 shows the asymmetry index $A I$, computed as in Eq. (3), for the station pairs which are tabulated in descending order of the mean of their absolute magnetic latitudes. The letters " $\mathrm{n}$ " and " $\mathrm{f}$ " indicate longitude sectors "near to" or "far from" the longitudes of the magnetic poles, which 
Table 1. Annual asymmetry of $N \mathrm{mF} 2$ from ionosonde and total content data. Magn. Lat. is absolute values of Corrected Geomagnetic Latitude.

\begin{tabular}{|c|c|c|c|c|c|}
\hline $\begin{array}{l}\text { Station pair } \\
\text { (letters A-Q as Fig. 1) }\end{array}$ & $\begin{array}{l}\text { Geographic } \\
\text { Lat, Long. }\end{array}$ & $\begin{array}{l}\text { Magn Lat. } \\
\text { N, S, Mean }\end{array}$ & $F_{10.7}$ & Noon & Midnight \\
\hline Y A Inverness-Campbell Is & 57N, 4W; 52S,169E & $55,60,58 \mathrm{n}$ & 140 & 0.13 & 0.16 \\
\hline z B Slough-Kerguelen & $52 \mathrm{~N}, 1 \mathrm{~W} ; 49 \mathrm{~S}, 70 \mathrm{E}$ & $49,58,54 n$ & $\begin{array}{l}100 \\
180\end{array}$ & $\begin{array}{l}0.08 \\
0.08\end{array}$ & $\begin{array}{l}-0.26 \\
-0.20\end{array}$ \\
\hline${ }^{\mathrm{z}} \mathrm{C}$ Wallops -Hobart & $38 \mathrm{~N}, 75 \mathrm{~W} ; 43 \mathrm{~S}, 147 \mathrm{E}$ & $50,54,52$ n & $\begin{array}{l}100 \\
180\end{array}$ & $\begin{array}{l}0.18 \\
0.24\end{array}$ & $\begin{array}{l}0.14 \\
0.15\end{array}$ \\
\hline Y D Poitiers-Christchurch & $47 \mathrm{~N}, \quad 0 \mathrm{E} ; 44 \mathrm{~S}, 173 \mathrm{E}$ & $43,48,46 n$ & 140 & 0.15 & 0.15 \\
\hline $\begin{array}{l}{ }^{\mathrm{S}} \text { E Washington-Watheroo } \\
{ }^{\mathrm{Y}} \mathrm{F} \text { San Francisco-Canberra }\end{array}$ & $\begin{array}{l}38 \mathrm{~N}, 75 \mathrm{~W} ; 30 \mathrm{~S}, 116 \mathrm{E} \\
37 \mathrm{~N}, 122 \mathrm{~W} ; 35 \mathrm{~S}, 149 \mathrm{E}\end{array}$ & $\begin{array}{l}50,42,46 n \\
43,45,44 n\end{array}$ & $\begin{array}{l}130 \\
140\end{array}$ & $\begin{array}{l}0.15 \\
0.18\end{array}$ & $\overline{0.21}$ \\
\hline${ }^{\mathrm{T}} \mathrm{G}$ Stanford-Auckland & $36 \mathrm{~N}, 122 \mathrm{~W} ; 37 \mathrm{~S}, 175 \mathrm{E}$ & $42,43,42 n$ & 150 & 0.22 & 0.22 \\
\hline H Eglin-Norfolk Is & 30N, 87W; 29S,168E & $42,36,39 n$ & 180 & 0.34 & 0.26 \\
\hline z J Wakkanai-Port Stanley & $45 \mathrm{~N}, 142 \mathrm{E} ; 52 \mathrm{~S}, 58 \mathrm{~W}$ & $38,37,38 \mathrm{f}$ & $\begin{array}{l}100 \\
180\end{array}$ & $\begin{array}{l}0.25 \\
0.19\end{array}$ & $\begin{array}{l}0.23 \\
0.15\end{array}$ \\
\hline${ }^{\mathrm{Y}} \mathrm{K}$ Grand Bahama-Brisbane & 27N, 78W; 28S,153E & $39,37,38$ n & 140 & 0.19 & 0.20 \\
\hline${ }^{\mathrm{Y}} \mathrm{L}$ Akita-Townsville & $40 \mathrm{~N}, 140 \mathrm{E} ; 19 \mathrm{~S}, 147 \mathrm{E}$ & $33,28,30 \mathrm{~m}$ & 140 & 0.31 & 0.25 \\
\hline${ }^{\mathrm{Y}}$ M Tokyo-Buenos Aires & $36 \mathrm{~N}, 140 \mathrm{E} ; 34 \mathrm{~S}, 58 \mathrm{~W}$ & $28,20,24 \mathrm{f}$ & 140 & 0.27 & 0.24 \\
\hline${ }^{\mathrm{N}} \mathrm{N}$ Maui-Rarotonga & $21 \mathrm{~N}, 156 \mathrm{~W} ; 21 \mathrm{~S}, 160 \mathrm{~W}$ & $21,21,21 \mathrm{~m}$ & 150 & 0.36 & 0.25 \\
\hline${ }^{\mathrm{T}} \mathrm{N}$ Honolulu-Rarotonga & $21 \mathrm{~N}, 156 \mathrm{~W} ; 21 \mathrm{~S}, 160 \mathrm{~W}$ & $21,21,21 \mathrm{~m}$ & 150 & 0.32 & 0.24 \\
\hline${ }^{\mathrm{E}} \mathrm{P}$ Singapore-Talara & $1 \mathrm{~N}, 104 \mathrm{E} ; 5 \mathrm{~S}, 81 \mathrm{~W}$ & $8,7,8$ e & 140 & 0.09 & 0.14 \\
\hline${ }^{\mathrm{Y}}$ Q Kodaikanal-Huancayo & $10 \mathrm{~N}, 78 \mathrm{E} ; 12 \mathrm{~S}, 75 \mathrm{~W}$ & $1,1,1$ e & 140 & 0.15 & 0.27 \\
\hline
\end{tabular}

\footnotetext{
${ }^{\mathrm{Y}}$ Results by Yonezawa (1971) (values for Grand Bahama include some data from Cape Canaveral and San Salvador);

${ }^{\mathrm{S}}$ data from Seaton and Berkner (1939); ${ }^{\mathrm{Z}}$ data from stations used by Zou et al. (2000); ${ }^{\mathrm{E}} 2002$ data; ${ }^{\mathrm{T}}$ total electron content data (Titheridge and Buonsanto, 1983; see Sect. 2.5). Corrected Geomagnetic Latitudes are computed at $300 \mathrm{~km}$ height for 1975; n=near-pole longitudes, f=far-from-pole longitudes, $m=$ mixed far/near pair, e=equatorial.
}

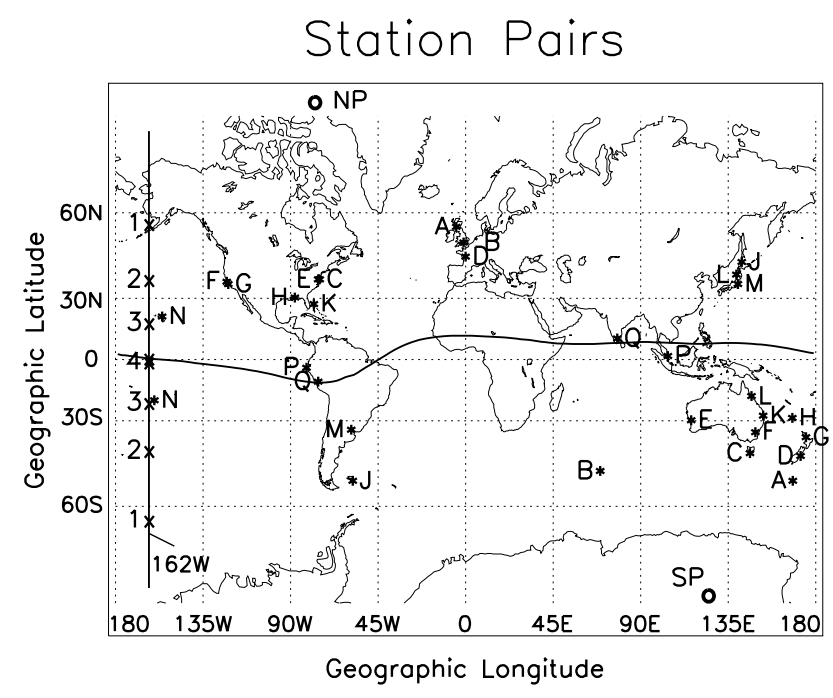

Fig. 1. Map of station pairs. Letters A-Q denote station pairs (Table 1). The vertical line with points $1-4$ marks the $162^{\circ} \mathrm{W}$ meridian discussed in Sect. 4.3. The heavy circles denote the north and south magnetic poles as used in the CTIP model, and the magnetic dip equator is shown. affects F2-layer seasonal behaviour, as can be seen in the maps of Torr and Torr (1973) and has been discussed by Rishbeth (1998) and Zou et al. (2000). Akita-Townsville and Maui-Rarotonga are "mixed near and far" pairs (m), and Huancayo-Kodaikanal and Singapore-Talara are "equatorial pairs" (e), respectively "geomagnetic" and "geographic". The problem of matching north and south stations becomes acute above about $45^{\circ}$ magnetic latitude. Here, at midday in "near-pole" longitudes, the (north + south) sum of $N m \mathrm{~F} 2$ is dominated by the large winter values and the summer values hardly matter at all. Table 1 includes two values derived from total electron content data (Sect. 2.5).

The ionosonde values of $A I$ from Table 1, shown by stars, are plotted against mean magnetic latitude in Fig. 2a for noon and Fig. 2b for midnight (Diamonds show CTIP results, discussed later). In general $A I$ decreases with increasing latitude, apart from low latitudes where the behaviour is erratic. There is no clear variation with latitude and no discernible difference between the values for "near-pole" and "far-from-pole" station pairs. AI is everywhere positive, except for Slough-Kerguelen at midnight, very likely because Kerguelen is then close to the auroral oval and often within it. In cases where two pairs may be considered as roughly equivalent (such as Wallops Island-Hobart and Washington-Watheroo, or else San Francisco-Canberra and 

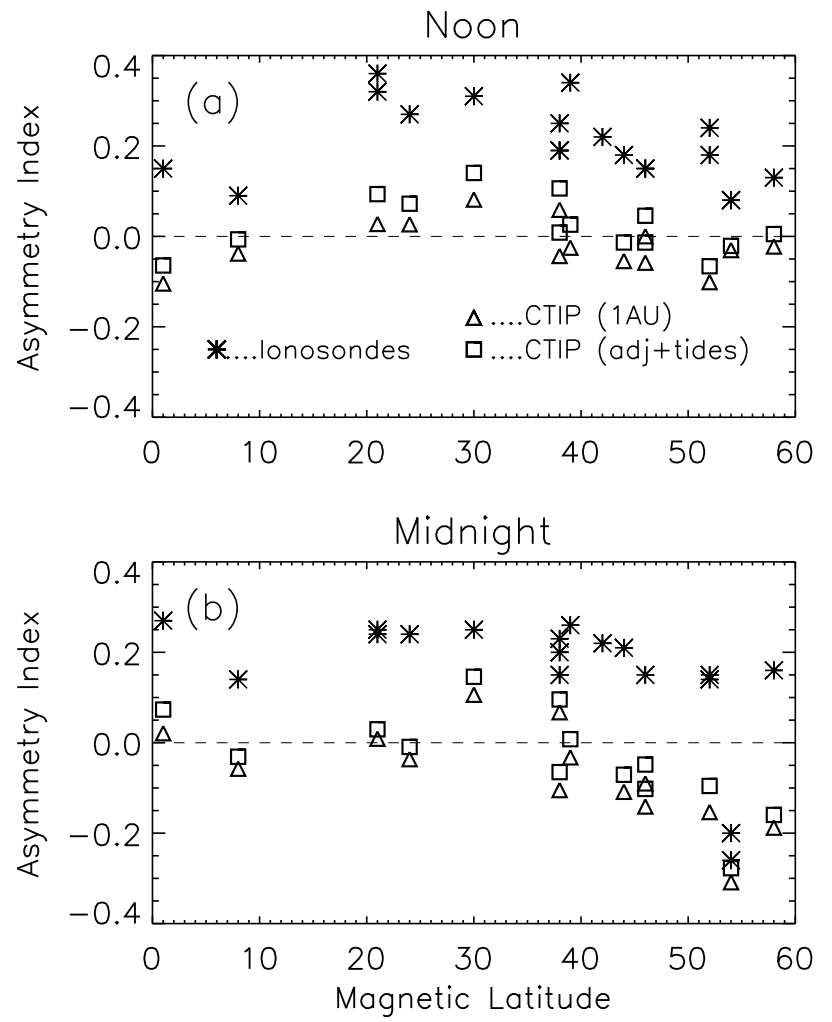

Fig. 2. Asymmetry index of $N m \mathrm{~F} 2$ for station pairs A-Q. Stars show values from ionosonde data, diamonds show CTIP values, computed with varying Sun-Earth distance. Above, noon; below, midnight. See Fig. 1 and Table 1 for station pairs. Midnight ionosonde values are not given for Singapore-Talara and Washington-Watheroo.

Stanford-Auckland), the values of $A I$ are similar but not identical, which shows that the values for $A I$ depend on pairing, though we cannot claim that the results are highly accurate.

We computed also the winter: summer ratio from Eq. (4), and found that usually $\mathrm{W}: \mathrm{S}>1$ by day, especially at solar maximum where $\mathrm{W}: \mathrm{S}$ may reach 5 . This implies that the asymmetry does depend largely on the seasonal (summer/winter) variation, which varies considerably from place to place, being greatest in high mid-latitudes in the "nearpole" North Atlantic and Australasian sectors. However, as shown below in Sect. 2.4, the asymmetry cannot be regarded entirely as a north-south imbalance in the summer/winter anomaly, because it exists at equatorial and other low latitudes where the predominant variation of noon $N m \mathrm{~F} 2$ is semiannual.

Yonezawa (1971) found that $A I$ (in his notation a/e) decreases with increasing sunspot number $R$, rapidly up to $R<50$ which roughly corresponds to $F_{10.7}=100$, and then more slowly. The data points in his Fig. 3 are averages over latitude zones. Our Fig. 3 displays the solar cycle be-

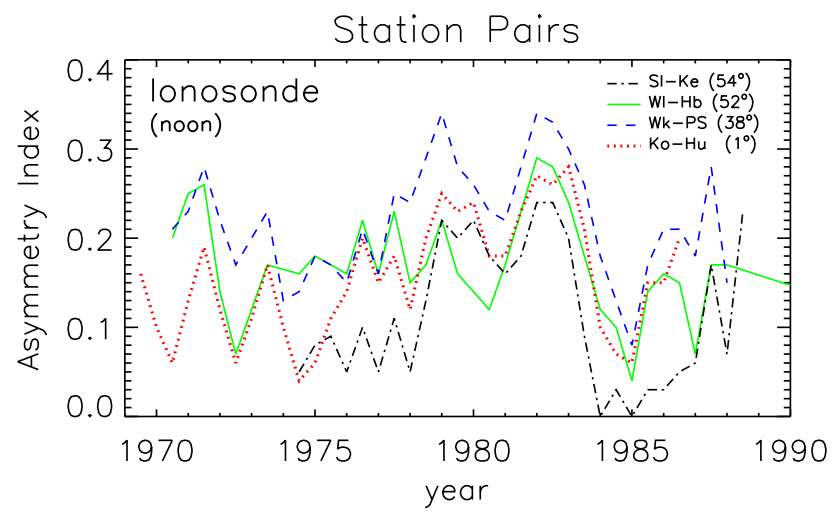

Fig. 3. Variation of the annual asymmetry in peak electron density at noon for four station pairs over two solar cycles, computed from ionosonde data.

Table 2. Asymmetry index in ionosonde $N \mathrm{mF} 2$ for SingaporeTalara (near geographic equator) and Kodaikanal-Huancayo (near geomagnetic equator).

\begin{tabular}{lrrr}
\hline Stations & Least & Median & Greatest \\
\hline Singapore-Talara (noon) & 0.08 & 0.09 & 0.14 \\
Singapore & -0.15 & -0.11 & -0.07 \\
Talara only & 0.28 & 0.31 & 0.38 \\
Singapore-Talara (midnight) & 0.08 & 0.14 & 0.35 \\
Singapore only & -0.01 & 0.12 & 0.36 \\
Talara only & 0.03 & 0.17 & 0.38 \\
Kodaikanal-Huancayo (noon) & 0.06 & 0.15 & 0.28 \\
Kodaikanal only & -0.06 & 0.10 & 0.22 \\
Huancayo only & 0.15 & 0.21 & 0.25 \\
\hline
\end{tabular}

haviour in more detail, showing noon $A I$ for four representative pairs, computed from January and July monthly means of $N m \mathrm{~F} 2$ over nearly two solar cycles. Each January point is computed from that January's data, and from the mean of the preceding and following July. Likewise, each July point is computed from that July's data, and from the mean of the preceding and following January. This smoothes out the erratic values of $A I$ that would otherwise be obtained when solar activity changes markedly in six months, as happens particularly at the start of solar cycles in 1977/1978 and 1987/1988. Figure 4 is similar, but is based on values of $N m \mathrm{~F} 2$ taken from the International Reference Ionosphere, IRI-2000. However, because of the limitations of IRI, we should probably put more trust in the actual ionosonde data.

In Fig. 3, $A I$ appears on the whole to be greater at solar maximum than at solar minimum, contrary to Yonezawa's findings, though, as it applies to only some of the particular cases listed in Table 2, we do not regard this as a firm conclusion. $A I$ is greatest at lower mid-latitudes around $30^{\circ}$, 


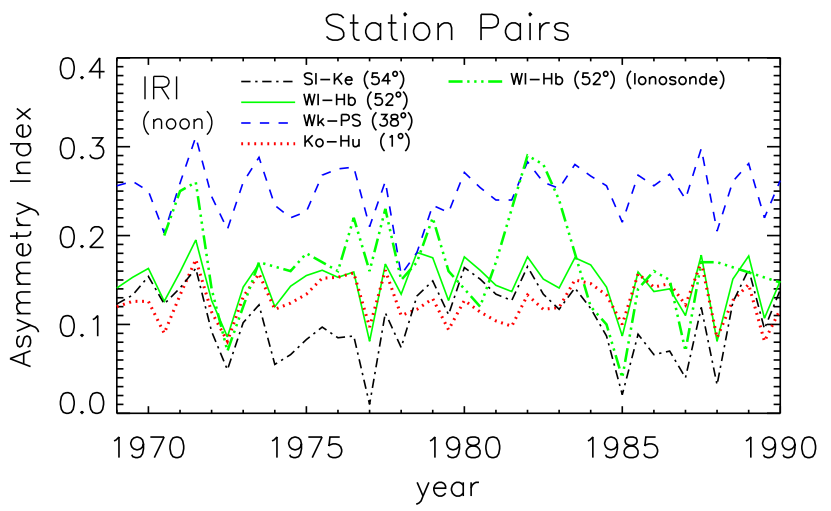

Fig. 4. Variation of the annual asymmetry in peak electron density at noon for four station pairs over two solar cycles, computed from the International Reference Ionosphere.

decreasing towards higher and lower latitudes. Except for the pair Slough-Kerguelen, for which $A I$ sometimes drops to zero, $A I$ is always positive and sometimes as large as 0.3 , corresponding to a January/July ratio of 1.8 in (north + south) $N m$ F2. The results from IRI (Fig. 4) show little coherence and do not agree well with the ionosonde results (which may say more about the IRI than about the ionosphere!).

We conclude from all these results that (i) the January/July asymmetry is real; (ii) it occurs both at noon and at midnight; (iii) it cannot reasonably be regarded as an accident of how stations are paired; (iv) it is much greater than the value 0.035 expected from the variation of Sun-Earth distance alone, and (v) on average it is greater at solar maximum than solar minimum. We have not looked for any effect of geomagnetic activity on AI, which could only be established by a much more extensive analysis and would be difficult to separate from a solar cycle variation.

\subsection{Equatorial stations}

Low latitudes provide an interesting test of the characteristics of the annual asymmetry, because winter/summer variations are weak or absent (though the semiannual variation is strong). Both magnetic and geographic equators are of possible interest. For the former, we have Yonezawa's pair Kodaikanal-Huancayo; for the latter, we use the pair Singapore-Talara; both pairs embrace Asian and American sectors. The available data sequences of $N m \mathrm{~F} 2$ are $1957-$ 1965 for Singapore-Talara and 1969-1986 for KodaikanalHuancayo, though the midnight data are limited, especially at the magnetic equator where the night F2-layer is highly structured and the critical frequency may not be welldetermined.

In the special case of the equator, one can in principle determine an "annual asymmetry" with data from one station only. Accordingly, for each pair we have computed AI for the Asian station alone; for the American station alone; and for both together (which of course is necessary for nonequatorial stations). Table 2 shows the least, median and greatest values of $A I$, to illustrate the considerable year-toyear scatter. We see that the American stations contribute more than the Asian stations to the combined $A I$; indeed, the mean daytime $A I$ for Singapore alone is negative.

These results suggest that in equatorial latitudes the annual asymmetry is quite strong in the American sector, but weak and possibly even reversed in the Asian sector. There is no very consistent pattern as to when the greatest and least values of $A I$ occur, but generally speaking, the greatest values of $A I$ tend to occur near solar minimum, the smallest near solar maximum. The results for paired stations are more consistent than those for single stations, which may contain a seasonal effect.

Electron densities in the low-latitude topside ionosphere, measured at $600 \mathrm{~km}$ height by the Hinotori satellite (inclination $31^{\circ}$ ), were analysed by Su et al. (1998). They found a very large annual asymmetry of around $100 \%$ by day and $30 \%$ at night. Using the Sheffield University Plasmasphere Ionosphere Model (SUPIM), they suggest that annual changes in the transequatorial neutral winds are largely responsible, together with changes of neutral composition. We discuss that in Sect. 3.1.

\subsection{Results for total electron content}

Does the annual asymmetry in $N m F 2$ exist also in TEC (the total electron content in a vertical column through the ionosphere)? Titheridge and Buonsanto (1983) measured TEC using beacon satellites, at four stations that form two good pairs, Stanford-Auckland and Honolulu-Rarotonga, in years around the low solar maximum of 1969/1970 (mean $F_{10.7} \approx 150$ ), and related their findings to changes in neutral composition. The results from these pairs are shown in Table 1 marked with small superscript "T", and are consistent with equivalent ionosonde values. Note that Maui and Honolulu are so close together that both are designated "N" in the table. In pairs " $F$ " and "G", the northern sites are close together, but the southern ones are far apart in longitude, though equivalent in geographic and magnetic latitude.

Titheridge and Buonsanto (1983) gave their results in terms of the mean, annual and semiannual Fourier components for day (10:00-16:00 LT) and night (22:00-02:00 LT). From these, we derived the annual asymmetry for each pair in two ways; first, by taking the annual/mean ratio from the sum of the Fourier terms for the north and south station (the results being shown in Table 1), and also by evaluating the January and July values from the Fourier series and applying Eq. (3), with very similar results. For comparison, Table 2 shows also the asymmetry index for $\mathrm{Nm} \mathrm{F} 2$ of ionosonde pairs Akita-Townsville (roughly comparable with StanfordAuckland) and Maui-Rarotonga (very nearly the same as Honolulu-Rarotonga), which agree quite well with those for TEC. The widespread existence of the annual asymmetry in 
Table 3. Annual asymmetry for pairs of points at 162W, at magnetic latitudes 60, 40, 20 and 0. CTIP values include varying Sun Earth distance. Neutral composition is computed at a fixed pressure-level. For further details see text. The only ionosonde comparison is with Maui/Rarotonga near pair 3, namely 0.36 for noon, 0.25 for midnight. Orbit effect is the difference (actual Sun-Earth distance - 1 AU). Tide effect is the difference (With tides) - (Without tides).

\begin{tabular}{|c|c|c|c|c|c|c|}
\hline Noon & $\begin{array}{c}\text { IRI } \\
N m \text { F2 }\end{array}$ & $\begin{array}{r}\text { CTIP } \\
\text { NmF2 }\end{array}$ & $\begin{array}{l}\text { CTIP } \\
\mathbf{O} / \mathbf{N}_{2}\end{array}$ & $\begin{array}{l}\text { CTIP } \\
\text { O/O }\end{array}$ & $\begin{array}{l}\text { CTIP } \\
P\end{array}$ & $\begin{array}{c}\text { MSIS } \\
\boldsymbol{P}\end{array}$ \\
\hline $1(60)$ & 0.22 & 0.13 & -0.02 & 0.01 & 9.5 & 10.2 \\
\hline $2(40)$ & 0.12 & 0.01 & -0.05 & -0.06 & 0.0 & 9.3 \\
\hline $3(20)$ & 0.24 & 0.13 & 0.04 & 0.07 & 0.3 & 7.6 \\
\hline $4(0)$ & 0.09 & -0.04 & 0.02 & 0.04 & -0.2 & 3.5 \\
\hline Average & 0.17 & 0.06 & 0.00 & 0.01 & 2.4 & 7.6 \\
\hline Orbit effect & & 0.04 & 0.00 & 0.01 & 0.3 & \\
\hline Tide effect & & 0.00 & 0.01 & -0.01 & 0.1 & \\
\hline \multicolumn{7}{|l|}{ Midnight } \\
\hline $1(60)$ & 0.14 & -0.03 & -0.16 & -0.16 & 0.8 & 10.4 \\
\hline $2(40)$ & 0.15 & 0.02 & -0.16 & -0.21 & -0.4 & 9.2 \\
\hline $3(20)$ & 0.28 & 0.07 & 0.10 & 0.14 & 0.2 & 7.2 \\
\hline $4(0)$ & 0.05 & -0.23 & 0.65 & 0.77 & -0.5 & 3.2 \\
\hline Average & 0.16 & -0.04 & 0.10 & 0.13 & 0.0 & 7.5 \\
\hline Orbit effect & & 0.03 & -0.01 & 0.00 & 0.4 & \\
\hline Tide effect & & -0.00 & 0.01 & 0.02 & 0.0 & \\
\hline
\end{tabular}

TEC has been confirmed by a new study of global data by Mendillo et al. (2005), with $A I$ averaging 0.15 over latitudes $0^{\circ}-65^{\circ}$. We conclude that the annual asymmetry in $N m \mathrm{~F} 2$ is not simply due to vertical redistribution of ionization.

\section{Neutral thermosphere}

\subsection{The MSIS model}

Since it is widely accepted that F2-layer electron density is closely related to the ambient neutral $\mathrm{O} / \mathrm{N}_{2}$ ratio, we now discuss the experimental data on that ratio, both from the global empirical MSIS model of the neutral thermosphere and from the AE-C dataset, which was among the sources used to construct MSIS. We consider computational results on the $\mathrm{O} / \mathrm{N}_{2}$ ratio and $N m \mathrm{~F} 2$ in Sect. 4.

The MSIS-86 (mass spectrometer/incoherent scatter) model (Hedin, 1987) is constructed from a variety of experimental data, obtained from instruments aboard rocket and satellites and indirectly from measurements of the ionized gas by ground-based incoherent scatter radars. Being based on actual data, MSIS naturally includes any effect of SunEarth distance. A great deal of averaging and smoothing, which would affect results at particular places, is used in constructing MSIS from the experimental data. This tends to smooth out latitude variations and features such as the peaks of $\mathrm{O} / \mathrm{N}_{2}$ ratio at high winter latitudes $\left(60^{\circ}-75^{\circ}\right)$ that are seen in unsmoothed data and simulations of the CTIP model. The ratios (in particular $\mathrm{O} / \mathrm{O}_{2}$ ) are subject to the serious difficulties of measuring this ratio by satellite-borne instruments.

The $\mathrm{O} / \mathrm{N}_{2}$ ratio is very height-dependent, so we examine a parameter related to composition that has the great advantage of being height-independent provided the atmosphere is diffusively separated, with each major constituent having its own scale height, as is accepted to be the case at F2-layer heights. This is the $P$-parameter (Rishbeth and Müller-Wodarg, 1999) given by

$P=28 \ln [\mathrm{O}]-16 \ln \left[\mathrm{N}_{2}\right]+12 \ln T$

where square brackets indicate gas concentration and $T$ is temperature. $P$ is especially useful for analyzing satellite data. Roughly speaking, an increase of 1 unit in $P$ corresponds to an increase of about $5.5 \%$ in $\mathrm{O} / \mathrm{N}_{2}$ ratio. As $P$ is logarithmic, Eq. (3) cannot be used to define a meaningful asymmetry. Instead, we specify the annual asymmetry in composition for a station pair by differences instead of ratios, thus:

$$
\begin{aligned}
& A I(P)= \\
& (P(\text { North })+P(\text { South }))_{\text {Jan }}-(P(\text { North })+P(\text { South }))_{\text {July }}(6)
\end{aligned}
$$

The annual asymmetry in $P$, as given by MSIS, is mostly due to composition rather than temperature. The small annual variation in exospheric temperature, about $\pm 10 \mathrm{~K}$ or 
Table 4. Noon annual asymmetry at pairs of stations for moderate solar activity $\left(F_{10.7} \sim 140\right)$. Ionosonde values are taken from Table 1 (and are averaged for the three pairs for which Table 1 values are at 100 and 180). CTIP values include varying Sun Earth distance. Neutral composition is computed at a fixed pressure-level. Orbit effect and tide effect as in Table 3. See text for further details.

\begin{tabular}{lrrrrrrrr}
\hline Noon & $\begin{array}{r}\text { Magn } \\
\text { Lat }\end{array}$ & $\begin{array}{r}\text { I'sonde } \\
N m \text { F2 }\end{array}$ & $\begin{array}{r}\text { CTIP } \\
N m \text { F2 } \\
\text { No tide }\end{array}$ & $\begin{array}{r}\text { CTIP } \\
N m \text { F2 } \\
\text { Tide }\end{array}$ & $\begin{array}{r}\text { CTIP } \\
\text { O/N2 } \\
\text { No tide }\end{array}$ & $\begin{array}{r}\text { CTIP } \\
\text { O/2 } \\
\text { No tide }\end{array}$ & $\begin{array}{r}\text { CTIP } \\
p\end{array}$ & $\begin{array}{r}\text { MSIS } \\
\text { No tide }\end{array}$ \\
\hline A Inverness-Campbell Is & 58 & 0.13 & 0.04 & 0.00 & 0.06 & 0.08 & 4.1 & \\
B Slough-Kerguelen & 54 & 0.08 & 0.01 & -0.02 & -0.07 & -0.10 & -5.4 & -0.6 \\
C Wallops Is-Hobart & 52 & 0.21 & -0.06 & -0.07 & -0.23 & -0.30 & -11.0 & 6.5 \\
D Poitiers-Christchurch & 46 & 0.15 & -0.01 & -0.01 & -0.04 & -0.04 & 0.6 & \\
E Washington-Watheroo & 46 & 0.15 & 0.04 & 0.05 & 0.01 & 0.03 & 2.7 & \\
F San Francisco-Canberra & 44 & 0.18 & -0.01 & -0.01 & -0.01 & -0.00 & 0.8 & \\
H Eglin-Norfolk Is & 39 & 0.34 & 0.02 & 0.03 & -0.01 & -0.00 & 0.9 & \\
J Wakkanai-Pt Stanley & 38 & 0.21 & 0.11 & 0.02 & 0.12 & 0.17 & 9.9 & 5.0 \\
K Grand Bahama-Brisbane & 38 & 0.19 & 0.00 & 0.01 & -0.05 & -0.05 & 1.6 & \\
L Akita-Townsville & 30 & 0.31 & 0.13 & 0.14 & 0.18 & 0.25 & 15.4 & \\
M Tokyo-Buenos Aires & 24 & 0.27 & 0.08 & 0.07 & 0.03 & 0.04 & 3.9 & \\
N Maui-Rarotonga & 21 & 0.36 & 0.08 & 0.09 & 0.07 & 0.10 & 2.4 & 9.6 \\
P Singapore-Talara & 8 & 0.09 & -0.00 & -0.01 & -0.17 & -0.21 & -1.9 & 4.8 \\
Q Kodaikanal-Huancayo & 1 & 0.15 & -0.07 & -0.06 & 0.04 & 0.07 & -1.0 & 5.6 \\
Average & & 0.20 & 0.026 & 0.016 & -0.01 & 0.00 & 1.4 & \\
Orbit effect & & & 0.046 & & 0.00 & 0.01 & 0.3 & \\
Tide effect & & & -0.010 & & 0.00 & 0.00 & 0.3 & \\
\hline
\end{tabular}

$\pm 0.8 \%$ with maximum in January, contributes $<1$ unit to $\mathrm{AI}(P)$ which is too small to matter. This applies also to the AE-C data (Sect. 3.2).

The last column of Table 3 gives $A I(P)$ from MSIS for four pairs of points, $1-4$, along the $162^{\circ} \mathrm{W}$ meridian (see Sect. 4.3), while the last columns of Tables 4 and 5 give $A I(P)$ for six station pairs covering a wide range of latitude. Comparing the values of $A I(P)$ with $A I$ of the observed $N m \mathrm{~F} 2$ (as computed from the IRI data in Table 3 and the ionosonde data in Tables 4 and 5), we find that the asymmetry of $N m \mathrm{~F} 2$ usually goes with an asymmetry in $P$ that is of the right order to account for the asymmetry in $\mathrm{NmF} 2$ (Slough-Kerguelen is an exception, but may well be influenced by Kerguelen's sub-auroral location, where the MSIS model may not be reliable). In every case, except WakkanaiPort Stanley, MSIS gives an algebraically greater asymmetry than CTIP, though the tabulated asymmetries in $P$ and $\mathrm{O} / \mathrm{N}_{2}$ ratio do not correspond very closely. This may be because $P$ is very nearly height-independent, while the $\mathrm{O} / \mathrm{N}_{2}$ ratio is derived on a fixed pressure-level near the F2 peak and (being so rapidly height-varying) can differ appreciably from the $\mathrm{O} / \mathrm{N}_{2}$ ratio actually at the peak. For that reason, the seasonal composition differences at $600 \mathrm{~km}$ height, derived by $\mathrm{Su}$ et al. (1998) from the SUPIM computational model, do not reliably represent the composition at the F2-peak.

\subsection{AE-C evidence for an annual variation in composition}

The AE-C data were obtained from the Neutral Atmosphere Temperature Experiment, NATE (Spencer et al., 1973) at altitudes between $200 \mathrm{~km}$ and $450 \mathrm{~km}$, acquired during 19751978 when the monthly mean solar $10.7 \mathrm{~cm}$ flux was in the range $70-100$ units. This dataset was used by Rishbeth et al. (2004) to investigate seasonal variations. The data were taken at all local times, but mostly daytime (09:0015:00 LT), though the variation of composition does not appear to vary much with local time.

We computed $P$ for quiet magnetic conditions $\left(K_{p} \leq 3\right)$, and also for disturbed conditions $\left(K_{p}>3\right)$ for which the AE$\mathrm{C}$ data are rather sparse. For the station pairs given in Table 4 , $A I(P)$ as given by Eq. (6) was positive for 8 stations, with average value $5 \pm 6$, for $K_{p} \leq 3$; for $K_{p}>3$ it was positive for all 11 stations, with average $8 \pm 6$. These averages respectively correspond to about $27 \%$ and $44 \%$ in $\mathrm{O} / \mathrm{N}_{2}$ ratio, with no discernible trend with latitude. Despite the rather large scatter between stations, this is experimental evidence that the annual asymmetry does exist in neutral composition, and is roughly sufficient to account for the annual asymmetry in $N m$ F2. This supports the conclusions drawn from MSIS in Sect. 3.1.

The AE-C results for north-south pairs of points along the $162^{\circ} \mathrm{W}$ meridian, however, are rather different. For these, $A I(P)$ given by Eq. (6) is positive at latitudes $40-67^{\circ}$ 
Table 5. Midnight annual asymmetry at pairs of stations for moderate solar activity $\left(F_{10.7} \sim 140\right)$. Ionosonde values are taken from Table 1 (and are averaged for the three pairs for which Table 1 values are at 100 and 180). CTIP values include varying Sun Earth distance. Neutral composition is computed at a fixed pressure- level. Orbit effect and tide effect as in Table 3. See text for further details.

\begin{tabular}{lrrrrrrrr}
\hline Noon & $\begin{array}{r}\text { Magn } \\
\text { Lat }\end{array}$ & $\begin{array}{r}\text { I'sonde } \\
N m \text { F2 }\end{array}$ & $\begin{array}{r}\text { CTIP } \\
N m \text { F2 } \\
\text { No tide }\end{array}$ & $\begin{array}{r}\text { CTIP } \\
N m \text { F2 } \\
\text { Tide }\end{array}$ & $\begin{array}{r}\text { CTIP } \\
\text { O/N } 2 \\
\text { No tide }\end{array}$ & $\begin{array}{r}\text { CTIP } \\
\text { O/2 } \\
\text { No tide }\end{array}$ & $\begin{array}{r}\text { CTIP } \\
p\end{array}$ & $\begin{array}{r}\text { MSIS } \\
\text { No tide }\end{array}$ \\
\hline A Inverness-Campbell Is & 58 & 0.16 & 0.15 & -0.16 & 0.16 & 0.23 & 3.5 & \\
B Slough-Kerguelen & 54 & -0.23 & 0.27 & -0.28 & 0.08 & 0.14 & 4.1 & -0.1 \\
C Wallops Is-Hobart & 52 & 0.14 & 0.11 & -0.11 & 0.18 & 0.21 & 10.9 & 6.4 \\
D Poitiers-Christchurch & 46 & 0.15 & -0.10 & -0.10 & 0.00 & 0.05 & 1.5 & \\
E Washington-Watheroo & 46 & - & -0.06 & -0.04 & & & & \\
F San Francisco-Canberra & 44 & 0.21 & -0.08 & -0.07 & -0.02 & -0.01 & 0.5 & \\
H Eglin-Norfolk Is & 39 & 0.26 & -0.01 & 0.01 & -0.04 & -0.05 & 1.0 & \\
J Wakkanai-Pt Stanley & 38 & 0.19 & 0.09 & 0.10 & 0.12 & 0.15 & 9.2 & 4.9 \\
K Grand Bahama-Brisbane & 38 & 0.20 & -0.08 & -0.06 & -0.08 & -0.10 & -1.4 & \\
L Akita-Townsville & 30 & 0.25 & 0.13 & 0.15 & 0.22 & 0.30 & 14.6 & \\
M Tokyo-Buenos Aires & 24 & 0.24 & -0.01 & -0.01 & 0.14 & 0.19 & 3.5 & \\
N Maui-Rarotonga & 21 & 0.25 & 0.03 & 0.03 & 0.14 & 0.120 & 2.5 & 9.7 \\
P Singapore-Talara & 8 & 0.14 & -0.02 & -0.03 & -0.11 & -0.13 & -2.0 & 4.8 \\
Q Kodaikanal-Huancayo & 1 & 0.27 & 0.06 & 0.07 & 0.05 & 0.08 & -1.2 & 4.1 \\
Average & & 0.17 & -0.042 & -0.036 & 0.02 & 0.05 & 1.1 & \\
Orbit effect & & & 0.030 & & -0.02 & -0.01 & 0.3 & \\
Tide effect & & & 0.006 & & 0.02 & 0.03 & 0.3 & \\
\hline
\end{tabular}

but negative at lower latitudes. Furthermore, Mendillo et al. (2005), using global data from only two days in July 2002 and January 2003, found that the $\mathrm{O} / \mathrm{N}_{2}$ ratio derived from the GUVI experiment on the TIMED satellite (Christensen et al., 2003), shows a smaller asymmetry of 0.06 , while the NRL MSIS thermospheric model has an even smaller asymmetry of 0.03 . We cannot expect complete consistency from every sample of data. It is interesting that in Figs. 5c, d, CTIP follows MSIS fairly well in $\mathrm{O} / \mathrm{N}_{2}$ ratio for latitudes below $30^{\circ}$ but poorly at higher latitudes.

\section{Computational results}

\subsection{The CTIP model and simulations}

We use the Coupled Thermosphere-Ionosphere-Plasmasphere (CTIP) model described by Fuller-Rowell et al. (1996) and Millward et al. (1996), much as used by Zou et al. (2000) but with improved vertical resolution of $1 / 2$ scale height, instead of one scale height as previously. The finer vertical resolution allows us to resolve tidal oscillations far better than before. There are now 31 pressure-levels, starting from the base of the thermosphere at height $h=80 \mathrm{~km}$ at which the atmospheric pressure is $p_{0}=1.04 \mathrm{~Pa}$. In most runs we included the annual variation of Sun-Earth distance, which Zou et al. (2000) neglected. The program computes the parameters of the neutral air and ionized plasma with a 1-min time step on a latitude/longitude grid $\left(2^{\circ} \times 18^{\circ}\right)$. The photochemistry does not include nitric oxide chemistry or the effects of vibrationally excited species. Some runs include tidal forcing at the lower boundary to account for dynamical coupling to the lower and middle atmosphere.

We assume a moderate level of solar activity, $F_{10.7}=100$ (or $F_{10.7}=180$ in some runs) and fairly quiet magnetic conditions, $A p=9$. Runs were made for the dates 4 January (Earth's perihelion) and 4 July (Earth's aphelion), in both cases for fixed Sun-Earth distance (1 astronomical unit, AU) and varying Sun-Earth distance (0.983 AU for January, 1.017 AU for July). As the CTIP routines assume that the solar radiation fluxes are proportional to $F_{10.7}$, we take the ionizing EUV and X-radiations to be proportional to $F_{10.7}$, which can only be a rough guide but has no real effect on our conclusions. We allow for the inverse-square dependence of incident flux on Sun-Earth distance by setting $F_{10.7}$ as 103.4 in January and 96.7 in July. At noon, the model is not far from steady state.

At low latitudes our version of CTIP does not compute the dynamo electric fields self-consistently, but uses the empirical field model by Richmond et al. (1980). We would not expect the fields to make much difference (except perhaps during magnetic storms or at night in the equatorial zone), either to $N m \mathrm{~F} 2$ or to neutral composition. Indeed, previous computations with CTIP (Rishbeth and Müller-Wodarg, 1999) show no sign of any such equatorial effect. At high 

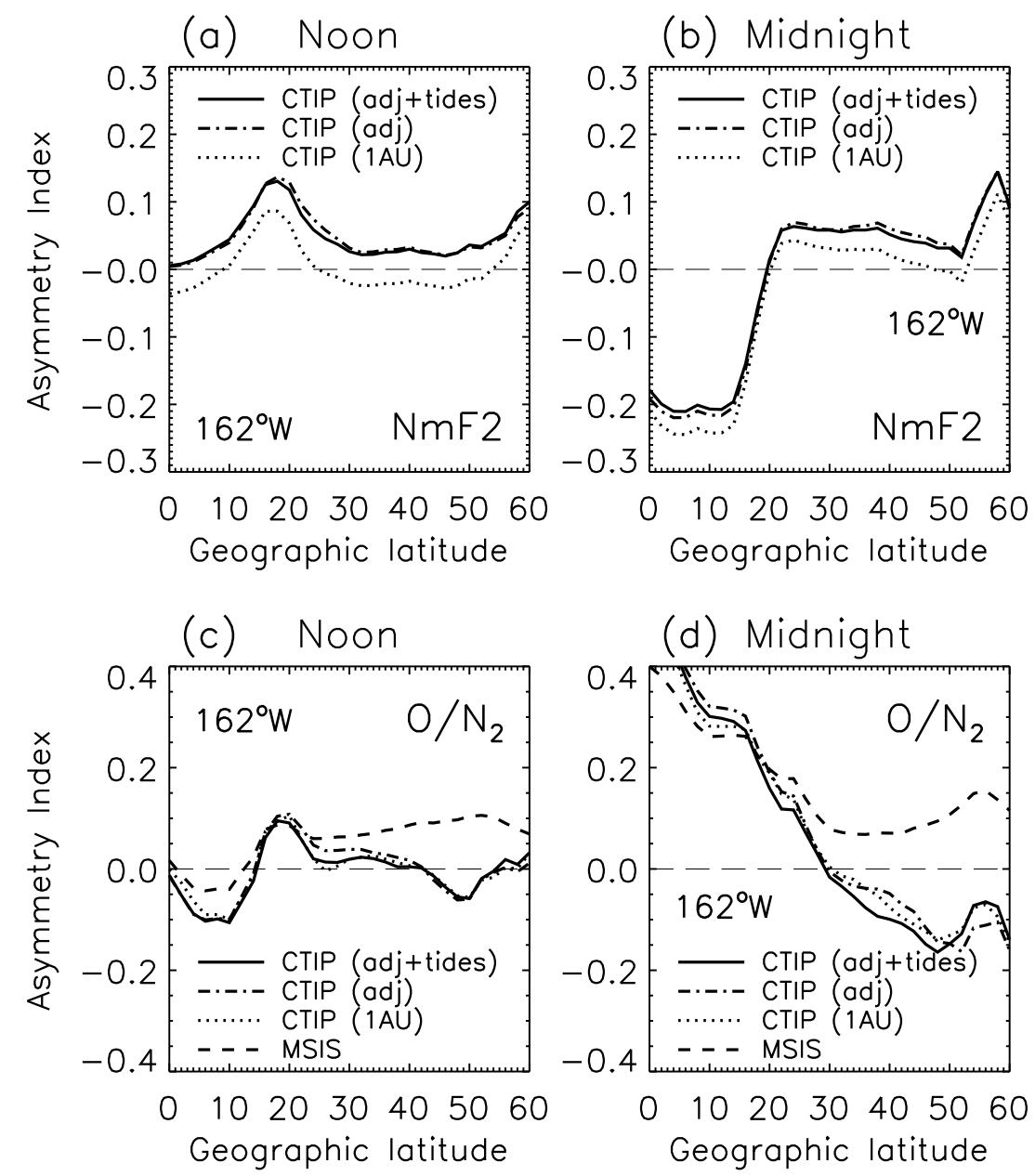

Fig. 5. Latitude variations at longitude $162^{\circ} \mathrm{W}$ Above: Asymmetry index of $N m \mathrm{~F} 2$ at noon and midnight. Dotted curves, CTIP, no mesospheric tides, Sun-Earth distance fixed at 1 AU. Solid curves: CTIP including mesospheric tides, adjusted for Sun-Earth distance. Below: Asymmetry index of neutral $\mathrm{O} / \mathrm{N}_{2}$ ratio at noon and midnight. Dotted curves, CTIP, no mesospheric tides, with Sun-Earth distance fixed at 1 AU. Solid curves: CTIP adjusted for Sun-Earth distance, including mesospheric tides. Dashed curves: Mass Spectrometer Incoherent Scatter Model (MSIS). In all CTIP cases, the values for "no tide", adjusted Sun-Earth distance' (not shown) are about 0.03 higher than the 1 AU values.

latitudes we assume the convection field parameterized by Foster et al. (1986) and the auroral precipitation pattern from NOAA/TIROS satellites parameterized by Fuller-Rowell and Evans (1987).

In addition to the solar and magnetospheric forcing of the thermosphere/ionosphere system in CTIP, in some runs we include at the lower boundary the effects of tides propagating upward from the lower and middle atmosphere. As described by Müller-Wodarg et al. (2001), the global diurnal and semidiurnal tides are implemented as perturbations of the height of the lower boundary pressure level and the horizontal winds and temperatures at that level. We assume westward propagating solar tides only and express their latitudi- nal structure using Hough functions, in accordance with the standard theory described by Chapman and Lindzen (1970). The external input to CTIP are the amplitudes and phases for the Hough modes, the diurnal $(1,1)$ mode and semidiurnal $(2,2),(2,3),(2,4)$ and $(2,5)$ modes, which describe a global profile of tidal oscillations at the bottom boundary level. Since we use propagating Hough modes only, tidal amplitudes in our simulations decrease towards the poles. The real atmosphere also includes considerable tidal waves at high latitudes which are described by vertically non-propagating Hough modes, but we ignore those in our study. The effects of including tides are discussed further in Sect. 5. 
4.2 Orbit effect: the influence of varying Sun-Earth distance on CTIP results

The annual variation of Sun-Earth distance is the most obvious first cause of the annual asymmetry. We computed how much the orbital variation increases $A I$, both at noon and at midnight, for four pairs of points on the $162^{\circ} \mathrm{W}$ meridian (see Sect. 4.3) and for the station pairs listed in Table 1. The results are shown as "Orbit effect" in Tables 3-5 and, as it varies so little between pairs, we just show the averages at the foot of each column.

On average the "orbit effect" contributes about 0.03 to the asymmetry of $N m \mathrm{~F} 2$, just as expected. In neutral composition the orbit effect is small and patchy (usually positive), but it is always greater for the $\mathrm{O} / \mathrm{O}_{2}$ than for the $\mathrm{O} / \mathrm{N}_{2}$ ratio. We return to this last point in Sect. 4.5.

\subsection{CTIP results for $N m \mathrm{~F} 2$ and composition on the $162^{\circ} \mathrm{W}$ meridian}

We now study the annual asymmetry, computed as in Eq. (3), along the $162^{\circ} \mathrm{W}$ meridian in the Pacific sector. This is one of the $18^{\circ}$ longitude steps in the CTIP model, and is near the longitude where the geographic and magnetic equators cross so the geographic and magnetic latitudes are nearly equal. This meridian is remote from both North and South magnetic poles and about as far from auroral effects as it is possible to get, so geomagnetic effects should be minimized.

For comparison, we take $N m \mathrm{~F} 2$ from the International Reference Ionosphere 2000 (IRI) (Bilitza, 2001). The only ionosonde pairs anywhere near this longitude are Maui and Rarotonga. To use the IRI, we found two January and two July quiet days in 1968 with similar conditions, computed AI for the four pairings of these days (which varied little among themselves), and averaged these values.

Table 3 shows the CTIP and IRI values of $A I$ for three north-south pairs of points (1-3) and for a single point (4) for the special case of the magnetic equator at $2^{\circ} \mathrm{S}$. Pair 1 may be influenced by auroral effects, which may not be well modelled by CTIP or IRI. Values of $A I$ for Pair 3 are similar to those for Maui-Rarotonga (Sect. 4.4), which in global terms are not far away. As an experiment, we tried using north-south pairs symmetric about the geographic equator, instead of pairs in magnetic latitude. In general the geographically symmetric pairs have slightly larger values of $A I$, by about 0.03 , than the magnetically symmetrical pairs, just as expected if the F2-layer structure is magnetically controlled. Table 3 also shows that the asymmetry in $P$-parameter (Eq. 6), derived from MSIS, is much stronger than in the CTIP results.

Panels (a, b) of Fig. 5 show the latitude variation of AI at longitude $162^{\circ} \mathrm{W}$, for noon and midnight $N m \mathrm{~F} 2$, for three cases of CTIP: fixed Sun-Earth distance and no imposed tides (dotted line), varying Sun-Earth distance without imposed tides (dashed-dotted line) and varying Sun-Earth distance with imposed semidiurnal tides (solid lines; see description in Sect. 5).

Panels (c, d) of Fig. 5 show how the asymmetry in the $\mathrm{O} / \mathrm{N}_{2}$ ratio varies with latitude. Again, the orbit effect is seen to be small (and again the effect of tides is too small to be shown). Below $15-20^{\circ}$ the asymmetry in $\mathrm{O} / \mathrm{N}_{2}$ ratio (similar for MSIS and for CTIP) varies quite sharply with latitude, and differently at noon and at midnight.

\subsection{CTIP results for pairs of stations}

Tables 4-5 show the asymmetries from CTIP computations for the pairs of points listed in Table 1. The station coordinates and ionosonde values of $N m \mathrm{~F} 2$ are as in Table 1 (values for the Zou et al. pairs, Slough-Kerguelen, Wallops IslandHobart and Wakkanai-Port Stanley are averages of $F_{10.7}=100$ and 180), and CTIP and MSIS values assume $F_{10.7}=100$. The $A I$ for $\mathrm{O} / \mathrm{N}_{2}$ and $\mathrm{O} / \mathrm{O}_{2}$ composition ratios are computed as in Eq. (3), at a fixed pressure-level near the daytime F2 peak. The average tide effect and orbit effect, at the foot of the appropriate columns, have been explained in Sects. 4.1 and 4.2.

The overall impression from Tables 4 and 5 is that, both at noon and midnight, the asymmetry given by CTIP is numerically smaller than in the ionosonde data. This is the heart of the puzzle! Much the same applies to the asymmetry in $P$ given by CTIP, compared to that given by MSIS, in every case except Wakkanai-Port Stanley. Although asymmetry in ionosonde $N m \mathrm{~F} 2$ usually goes with asymmetry in MSIS $P$, the asymmetries in CTIP $N m \mathrm{~F} 2$ and $P$ seem only loosely related, though we think the link is real.

As found in the ionosonde data (Sect. 2.3), at latitudes above about $45^{\circ}$ the annual asymmetry in CTIP $N m \mathrm{~F} 2$ is closely connected to the seasonal (summer/winter) variation, which varies considerably from place to place. We made experiments in which one station of a pair was changed, and found that the re-computed $A I$ depends on whether the stations involved are in or out of a zone of large winter $\mathrm{NmF} 2$. This may explain why the Wallops Island-Hobart pair stands out in the CTIP simulations.

According to CTIP, the globally averaged $\mathrm{O} / \mathrm{O}_{2}$ ratio increases from July to January by about $18 \%$ for varying SunEarth distance, but only $11 \%$ for fixed Sun-Earth distance. For the $\mathrm{O} / \mathrm{N}_{2}$ ratio the corresponding figures are $10 \%$ and $7 \%$.

4.5 The F2-layer loss coefficient and Buonsanto's hypothesis

Buonsanto's hypothesis about $\mathrm{O}_{2}$ dissociation involves F-layer photochemistry. In the standard theory of the daytime F2 peak, photoionization (rate $q$ ), which depends mainly on the atomic oxygen concentration [O], approximately balances photochemical loss. The loss coefficient $\beta$ depends on the molecular nitrogen and oxygen concentrations, $\left[\mathrm{N}_{2}\right]$ and $\left[\mathrm{O}_{2}\right]$. Neglecting transport processes (which 
only become really dominant at heights above the F2 peak, though they control where the peak forms), the peak electron density is approximately given by the steady-state formula

$N m \mathrm{~F} 2 \approx q / \beta \approx I_{\infty}[\mathrm{O}] /\left(k^{\prime}\left[\mathrm{O}_{2}\right]+k^{\prime \prime}\left[\mathrm{N}_{2}\right]\right)$

where $k^{\prime}, k^{\prime \prime}$ are the relevant rate coefficients and the ionization rate $I_{\infty}$ is proportional to the flux of solar ionizing radiation and a weighted mean of ionization cross-sections for the neutral constituents. Although $\mathrm{N}_{2}$ is more abundant than $\mathrm{O}_{2}$ by a factor of 10-20, the rate coefficients are such that $k^{\prime}$ exceeds $k^{\prime \prime}$ by a similar factor (except when the $\mathrm{N}_{2}$ is vibrationally excited and $k^{\prime \prime}$ is enhanced, which is not generally thought to be the case in quiet geomagnetic conditions at mid-latitudes). Thus both the $\mathrm{O}_{2}$ and $\mathrm{N}_{2}$ terms are likely to be important in Eq. (7) and, as solar radiation dissociates $\mathrm{O}_{2}$ much more strongly than $\mathrm{N}_{2}$, variations of Sun-Earth distance affects the $\mathrm{O} / \mathrm{O}_{2}$ ratio more than the $\mathrm{O} / \mathrm{N}_{2}$ ratio (though the latter is affected by the change in $\mathrm{O}$ concentration caused by dissociation of $\mathrm{O}_{2}$ ). We therefore wish to see how much the summer/winter change of atomic/molecular ratio is modified by the extra change in $\mathrm{O}_{2}$ dissociation due to changing Sun-Earth distance.

In almost every case we computed with CTIP (Tables 3-5), we found the annual asymmetry is indeed greater in $\mathrm{O} / \mathrm{O}_{2}$ than in $\mathrm{O} / \mathrm{N}_{2}$, but only by about 0.02 on average (and about the same is found in MSIS). This difference is much too small to affect the conclusion that CTIP does not reproduce the observed asymmetries. So can we explain the annual asymmetry of $N m \mathrm{~F} 2$ in terms of the $\mathrm{O} / \mathrm{O}_{2}$ ratio, as suggested by Buonsanto?

Our answer is "no, but it helps". With the exceptions of the pairs Inverness-Campbell Island and Slough-Kerguelen (of which the southern stations are sub-auroral) and AkitaTownsville, the asymmetry even in the $\mathrm{O} / \mathrm{O}_{2}$ ratio is too small to correspond to the ionosonde observations.

Buonsanto's hypothesis would work best if the $\mathrm{O}_{2}$ loss process dominates. So, as a further and probably decisive test, we did a computing experiment by supposing that $k^{\prime}$ is so much greater than $k^{\prime \prime}$ that only the $\mathrm{O}_{2}$ loss process matters. To that end, we ran CTIP with the $\mathrm{N}_{2}$ loss process disabled, while doubling the rate coefficient $k^{\prime}$ of the $\mathrm{O}_{2}$ loss process to keep the mean electron density roughly the same, in order that other factors in CTIP that depend on the ionization, such as thermal processes, would be more-or-less unchanged. We did the calculations for a fixed pressure-level near the midlatitude F2 peak, rather than at the peak, but that should make little difference to the conclusions.

We found that our hypothetical assumption of "loss via $\mathrm{O}_{2}$ only" increases the asymmetry $A I$ only by about 0.01 , as compared to that with $\mathrm{O}_{2}$ and $\mathrm{N}_{2}$ loss processes together. This increase is barely noticeable, so we have to abandon Buonsanto's hypothesis, ingenious as it is, as an explanation of the F2-layer annual asymmetry. As a further detail, our computing experiment made little change to $N m \mathrm{~F} 2$, which implies that the $\mathrm{N}_{2}$ and $\mathrm{O}_{2}$ loss processes are of similar importance at the $\mathrm{F} 2$ peak.

\section{Thermospheric mixing by waves}

In the following we investigate the question of F-region coupling to the neutral atmosphere via composition changes and thereby investigate how far the observed January/July asymmetry in $N m \mathrm{~F} 2$ could be generated by the neutral atmosphere. In order for the F2-layer January/July asymmetry to be linked to processes in the neutral atmosphere, the asymmetry would need to be present also in the thermosphere, in particular the $\mathrm{O} / \mathrm{N}_{2}$ or $\mathrm{O} / \mathrm{O}_{2}$ ratios, both of which correlate with the electron densities. In Sect. 3.1 we showed that a January/July asymmetry could indeed be found in neutral composition from the MSIS model. In the following we investigate what processes can cause this asymmetry in the neutral gases. In Sect. 4 we showed that the CTIP model does not generate the observed January/July asymmetry either in the ionosphere or thermosphere. In the simulation discussed there we ignored coupling to lower regions in the atmosphere, so now we focus on the question of whether coupling to the regions below the thermosphere could be responsible for the neutral gas asymmetry found in MSIS.

\subsection{Tides and composition}

Tides are global oscillations in the atmosphere which are generated either thermally ("solar tides") or gravitationally ("lunar tides", plus a minor solar component) and propagate horizontally and vertically in the atmosphere. Solar tides are generated through absorption of solar radiation, primarily by water in the troposphere or ozone in the stratosphere, whereas lunar tides are a result of the Moon's gravitational pull on the atmosphere. In general, solar tides are dominant over lunar tides.

As tides or other waves propagate upward in the atmosphere, their amplitudes grow with height roughly as the inverse square root of the mass density. When amplitudes reach critical values, they cause convection and turbulence and other damping processes that become important and limit the further amplitude growth. At that point, some of the wave energy and momentum is deposited in the background atmosphere, affecting temperatures and winds. Thus momentum and energy originating in the lower atmosphere is transported to higher regions in the atmosphere by tides or other waves.

In the thermosphere, the main wave damping processes are viscosity and vertical thermal conduction. While many of the higher frequency waves dissipate or break in the middle atmosphere, global scale waves such as tides and planetary waves are commonly found in the lower thermosphere. Typically, planetary waves and the diurnal tide dissipate below $100 \mathrm{~km}$ altitude, while the semidiurnal tides can reach $200 \mathrm{~km}$. Tides can have periods of up to a day or fractions 
thereof, the most prominent ones found in the lower thermosphere having periods of $24 \mathrm{~h}, 12 \mathrm{~h}$ and $8 \mathrm{~h}$. Up to around $120 \mathrm{~km}$, tides dominate the daily variability of thermospheric temperatures and winds.

Solar and lunar tides are also observed in the ionosphere, where they produce drift motions of the plasma. However, away from the special circumstances of the geomagnetic equatorial zone, these tidal drifts do not directly produce marked effects on $N m \mathrm{~F} 2$. In the non-auroral ionosphere, $N m \mathrm{~F} 2$ is largely controlled by photochemistry and, as shown in Eq. (7), is linked to the neutral $\mathrm{O} / \mathrm{O}_{2}$ and $\mathrm{O} / \mathrm{N}_{2}$ ratios. It is through this link that tides may have their strongest effect on $N m \mathrm{~F} 2$, as explored in the following.

Akmaev and Shved (1980) first suggested an influence of the upward propagating diurnal tide on atomic oxygen densities in the thermosphere. The mechanism they proposed is associated with the fact that vertical displacement of atomic oxygen by the diurnal tide in the lower thermosphere enhances the effective three-body recombination rate, reducing the atomic oxygen densities and creating a more molecular atmosphere. Similar results were obtained by Forbes et al. (1993) and Fesen (1997), using the TIME-GCM model. Their results show that both the diurnal and semidiurnal solar tides reduce the abundances of atomic constituents in the thermosphere through the same process as originally proposed by Akmaev and Shved (1980). In addition, these calculations predict a decrease of electron densities in the F-region by up to $20 \%$ caused by diurnal and semidiurnal propagating tides originating from below the thermosphere. Fuller-Rowell (1998) proposed an alternative process, by which the seasonal inter-hemispheric flow leads to stronger mixing of the thermosphere at the solstices compared with equinoxes, leading to more effective diffusive separation of constituents at equinox and thus a less molecular atmosphere. This was proposed as a mechanism to explain semiannual variations in neutral densities, which also affect the ionosphere.

What these studies have shown is (a) how dynamics can affect neutral composition in the thermosphere through the effect of mixing either by waves or by large scale interhemispheric circulation and (b) that this potentially affects ionospheric plasma densities through changes in the recombination rates for ions. What none of these studies have shown is whether these processes could explain the ionospheric January/July asymmetry, and it is this question we attempt to explore in the following.

\subsection{Model runs}

In order to investigate the effects of tides on the January/July asymmetry, we ran CTIP for several cases which included tidal forcing at the lower boundary, implemented in the way described in Sect. 4.1, using the diurnal $(1,1)$ Hough mode and semidiurnal $(2,2),(2,3),(2,4)$ and $(2,5)$ modes. We ran two cases of tidal forcing. Case 1 was run for 4 January and
4 July, assuming different tidal amplitudes, namely: January: $(1,1) 100 \mathrm{~m} / 12.0 \mathrm{~h} ;(2,2) 355 \mathrm{~m} / 3.8 \mathrm{~h} ;(2,3) 84 \mathrm{~m} / 13.3 \mathrm{~h} ;(2,4)$ $76 \mathrm{~m} / 5.4 \mathrm{~h} ;(2,5) 118 \mathrm{~m} / 4.4 \mathrm{~h}$ and July: $(1,1) 200 \mathrm{~m} / 12.0 \mathrm{~h}$; $(2,2) 266 \mathrm{~m} / 4.0 \mathrm{~h} ;(2,3) 56 \mathrm{~m} / 3.1 \mathrm{~h} ;(2,4) 52 \mathrm{~m} / 10.1 \mathrm{~h} ;(2,5)$ $87 \mathrm{~m} / 10.7 \mathrm{~h}$. On average, therefore, we reduced the semidiurnal amplitudes by a factor of 1.4 in July in Case 1, while doubling the diurnal amplitude. This is consistent with the climatology by Forbes and Vial (1989), although we enhanced the overall strength of tidal forcing in our model to strengthen the potential effect. Case 2 was run for 4 January and 4 July as well as for the March and September equinoxes, assuming for all months tidal amplitudes and phases of $(1,1) 100 \mathrm{~m} / 12.0 \mathrm{~h} ;(2,2) 400 \mathrm{~m} / 3.8 \mathrm{~h} ;(2,3) 300 \mathrm{~m} / 3.8 \mathrm{~h} ;(2,4)$ $200 \mathrm{~m} / 5.4 \mathrm{~h} ;(2,5) 100 \mathrm{~m} / 4.4 \mathrm{~h}$. All tidal runs for January and July include the variation of Sun-Earth distance as described in Sect. 4.1 and differ from those simulations only with respect to tidal forcing.

\subsection{Tidal effects on $\mathrm{NmF} 2$ computed from CTIP}

Tables 3-5 summarize the results of our simulations with Case 1 tidal forcing, which indicate that tides have a small effect only on the strength of the January/July asymmetry both in neutral composition and $N m F 2$. Since our tidal amplitudes, based on the climatology by Forbes and Vial (1989), are assumed to differ between January and July by only a factor of 1.4 , we furthermore calculated the annual asymmetry indices for a tidal January and non-tidal July simulation (and vice versa), thus maximizing the difference in lower boundary forcing, but found very similar results irrespective of the tidal forcing. While we find a general difference between $N m \mathrm{~F} 2$ with and without tidal forcing, in agreement with results by Forbes et al. (1993) and Fesen (1997), we are unable to enhance the January/July asymmetry with the tides. We find the tidal effect on composition to be in the same sense at all local times, which implies that the tidal effect is "rectified" with a time constant greater than $24 \mathrm{~h}$. We may conclude that the tides have a "stirring-up" effect on thermospheric composition, which acts to increase the molecular/atomic ratio in the thermosphere and decrease electron densities, smoothing out local time variations, as expected since thermospheric composition takes about 20 days to settle (Rishbeth et al., 2000a). This tends to confirm that the effects on $N m \mathrm{~F} 2$ are not due directly to the oscillatory drifts in the F2-layer plasma, which have little net effect on the electron density at mid-latitudes.

The weak influence of tides in our simulations at first appears to contradict the findings by Forbes et al. (1993) so, to verify the consistency of CTIP with the TIGCM Model which they used, we carried out simulations for identical seasonal and tidal conditions as they. We found the same decrease in F-region electron density and $\mathrm{O} / \mathrm{N}_{2}$ ratio as they did, confirming that CTIP reproduces correctly the underlying physical processes and thereby validating our model. Since the January/July asymmetry assumes solstice 

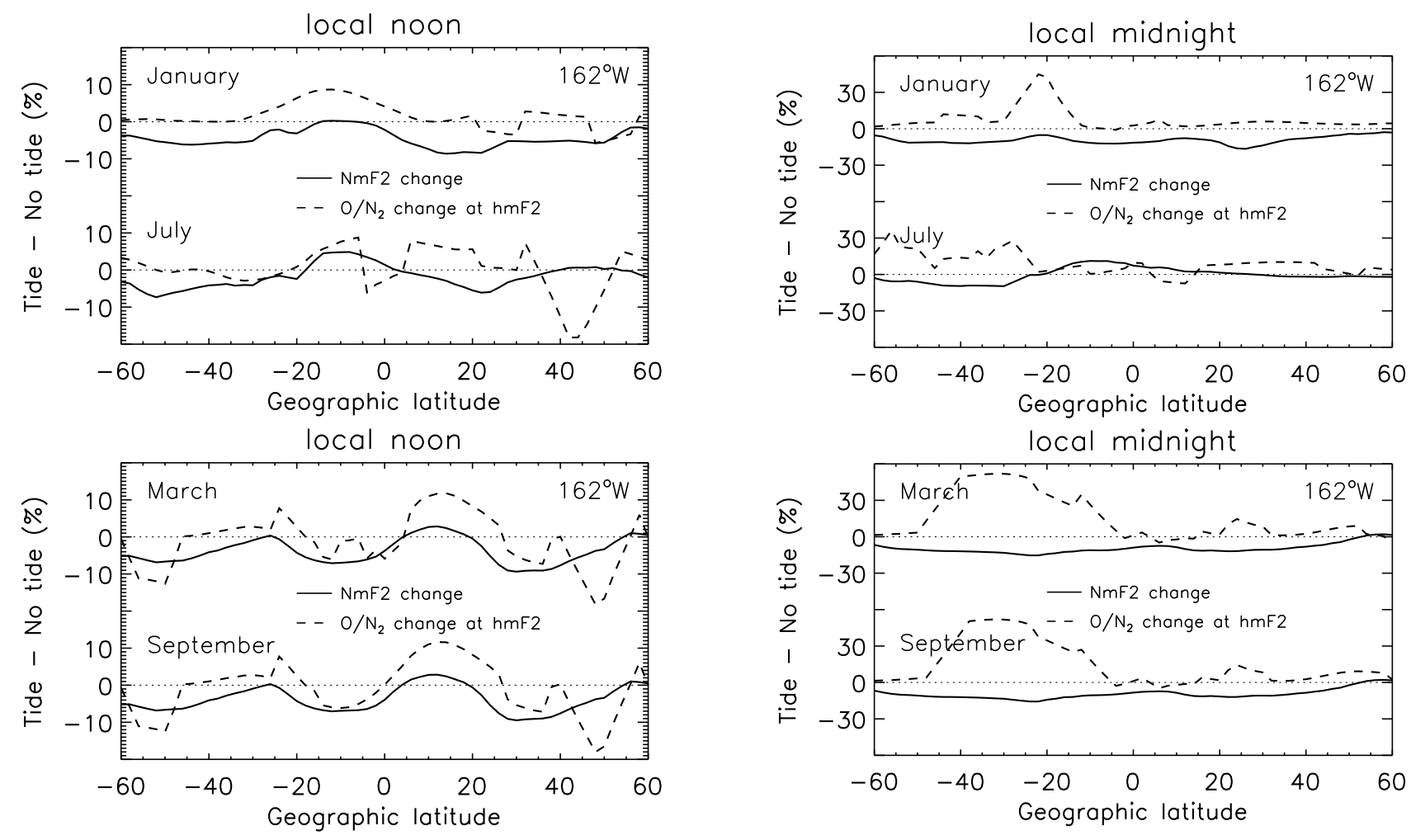

Fig. 6. Effect of mesospheric tides on values of asymmetry index, as percentage of non-tide values. Above: Solstices, Below: Equinoxes. Full curves: Peak electron density. Dashed curves: Neutral $\mathrm{O} / \mathrm{N}_{2}$ ratio at the height of the F2-peak. All curves are for local noon.

and not equinox conditions, we will in the following examine whether seasonal conditions could affect the tidal influences on neutral and ion composition.

Figures 6 and 7 show results from our Case 2 simulations, which assumed the same tidal amplitudes at all seasons. Shown are the normalized changes $\left(A I_{\text {tidal }}-A I_{\text {non-tidal }}\right) /$ $A I_{\text {non-tidal }}$ of the asymmetry index $A I$ due to tidal forcing in the model versus geographic latitude. Solid lines are changes of $N m \mathrm{~F} 2$, dashed lines are those of $\mathrm{O} / \mathrm{N}_{2}$ taken at the height of peak electron density $h m \mathrm{~F} 2$. The upper panels show changes at January and July, the bottom panels are changes at the equinoxes. All values are shown along the $162^{\circ} \mathrm{W}$ meridian to minimize effects due to the offset of the geographic and geomagnetic poles. Figure 6 shows values at local noon, Fig. 7 at local midnight. We see that noon changes of $N m \mathrm{~F} 2$ in general shape correlate well with those of $\mathrm{O} / \mathrm{N}_{2}$, confirming our expectation (see Sect. 4.5) from photochemical considerations, but at the same time some deviations between the dashed and solid curves are present which suggest the influence of plasma transport. The correlation between $N m \mathrm{~F} 2$ and $\mathrm{O} / \mathrm{N}_{2}$ is less apparent on the nightside (Fig. 7), where changes of $\mathrm{O} / \mathrm{N}_{2}$ reach far greater values than on the day-

Fig. 7. As Fig. 6 for local midnight.

side, in particular at equinox, but those of $N m \mathrm{~F} 2$ are fairly invariant. Nighttime $N m \mathrm{~F} 2$ is more strongly controlled by transport.

The response of $\mathrm{O} / \mathrm{N}_{2}$ at F2-layer altitudes to tidal forcing strongly depends upon latitude, as does the structure of tides. At equatorial latitudes, where tidal forcing amplitudes are largest, we find an enhancement of $\mathrm{O} / \mathrm{N}_{2}$ at the solstices (upper panels of Fig. 6), whereas towards high mid-latitudes $\left(40^{\circ}-60^{\circ}\right)$ more complexity is apparent which suggests the influence of high latitude forcing (in particular through ion drag). We found the behaviour at E-region altitudes (not shown) to be far more uniform and symmetric with latitude and not to include those higher latitude features. Tides overall appear to decrease $\mathrm{O} / \mathrm{N}_{2}$ on the dayside at some latitudes, but we equally find regions where the value has increased with tidal forcing. So, the picture appears to be more complicated than the simple idea that mixing due to tides increases the abundance of molecular constituents and hence decrease $\mathrm{O} / \mathrm{N}_{2}$. At local midnight (Fig. 7), large tidally induced changes are apparent in $\mathrm{O} / \mathrm{N}_{2}$, particularly at the equinoxes, but that hardly affects $N m \mathrm{~F} 2$ which is controlled primarily by transport processes.

Interesting differences are apparent between the responses at solstice (upper panels in Figs. 6 and 7) and equinox (lower panels). At equinox the response to tidal forcing is generally stronger than at solstice, on average $10-15 \%$ as opposed 
to $5-10 \%$. This effect is even stronger at E-region altitudes (not shown). This result is interesting in that it shows that the way in which tides affect the thermosphere depends on the background circulation, which is different at equinox and solstice.

As outlined by Duncan (1969) and described by Rishbeth et al. (2000a), a summer-to-winter hemisphere circulation cell is present in the thermosphere at solstice, with average meridional wind velocities of around $25 \mathrm{~m} \mathrm{~s}^{-1}$. This in itself causes a departure of the gas distribution from diffusive equilibrium, as noted also by Fuller-Rowell (1998), and the effect of tides on composition at the solstices is hence reduced. At equinox, in contrast, the low-to mid-latitude thermosphere in the absence of tides is undisturbed overall and close to equilibrium distribution, so tidal disturbances generate an overall stronger response. The well-defined latitudinal responses in Figs. 6 and 7 show that the main effect on neutral composition is via the effect of tides on the background circulation, altering the vertical velocities. Since this effect depends upon the magnitude of background (diurnally averaged) winds at a particular location, which themselves depend on latitude, we see pronounced latitudinal variations. So, the tidal effect on $\mathrm{O} / \mathrm{N}_{2}$ at F2-layer altitudes is not a general 'stirring-up' of the atmosphere, but a more localized effect via the manner in which background horizontal and vertical winds are altered due to wave dissipation.

In principle, plasma transport along magnetic field lines due to neutral winds also affect the recombination rate of ions, and hence $N m \mathrm{~F} 2$. However, we find tidal dissipation primarily affects the zonal and vertical velocities and to less extent the meridional ones. Since we assumed westward propagating tides only, zonal winds generally experience westward acceleration. This has little effect on plasma densities, except to some extent in the dawn and dusk sectors.

In summary, we found daytime $\mathrm{O} / \mathrm{N}_{2}$ and $N m \mathrm{~F} 2$ to respond overall similarly to tidal forcing, but this response is strongly latitude dependent. At night, tidal changes to $\mathrm{O} / \mathrm{N}_{2}$ are more pronounced, but those of $N m \mathrm{~F} 2$ are similar to or smaller than daytime changes. The thermosphere appears to respond less strongly to tidal forcing at solstice than at equinox. This behaviour helps us understand the weak effect that tides have on the January/July asymmetry: while locally there is an effect, it is too weak to alter our results significantly from the non-tidal runs.

\subsection{Waves not included in the computations}

In our simulations we ignored non-propagating tides as well as planetary waves and gravity waves. By non-propagating tides we mean atmospheric tides that do not propagate in the vertical direction, but horizontally only. Their occurrence and effects on the atmosphere are therefore largely limited to the height region where they are excited. This is primarily in the troposphere and stratosphere, far below our region of interest, justifying our assumption.
Because of the coarse grid size in longitude, CTIP cannot represent the propagation of planetary waves. Although gravity waves of various periods are a well-known feature of the F2-layer, the mere passage of a gravity wave does not seem to have any lasting effect on the electron density. Again as with tides, the most important effect of gravity waves (so far as the present work is concerned) is likely to be enhanced mixing in the lower thermosphere. Their forcing is greatest in the Northern Hemisphere in winter, partly as a result of topography and partly because of seasonally varying zonal winds that modulate the upward propagation of gravity waves. Gravity waves (other than solar tides) are not included in the CTIP version used in this paper.

\section{Are there annual variations in other ionospheric pa- rameters?}

\subsection{Height of F2 peak}

In their study of semiannual variations of the $\mathrm{F} 2$ peak height $h m \mathrm{~F} 2$, Rishbeth et al. (2000b) also derived 12-month components for sixteen stations, including three of the pairs listed in Table 1. The three northern stations of these pairs (Slough, Wakkanai, and Washington/Wallops Island) have maximum noon $h m \mathrm{~F} 2$ in early summer (April-May), while the southern stations (Kerguelen, Port Stanley, and Mundaring (which replaced Watheroo)) have maximum $h m \mathrm{~F} 2$ in late summer (January-February). Thus on average the annual asymmetry in $h m \mathrm{~F} 2$ peaks around March equinox. The corresponding amplitudes are $10-20 \mathrm{~km}$ for the northern three stations, about $20 \mathrm{~km}$ for Kerguelen and Mundaring, and no less than $40 \mathrm{~km}$ for Stanley, where the large amplitude is attributed to the strong, seasonally varying meridional winds in the South Atlantic sector. As discussed in Sect. 7.5, the hemispheric imbalance in the winds may have implications for the annual asymmetry of $N m \mathrm{~F} 2$.

\subsection{E-layer electron density $\mathrm{NmE}$}

We have looked for an asymmetry in noon E-layer electron density for the "Zou et al. pairs" of stations, using Eq. (3) with $N \mathrm{mE}$ instead of $N m \mathrm{~F} 2$. The E-layer data for the six stations contained many missing values, but nevertheless the annual asymmetry could be estimated, though not with high accuracy. Averaging over low and high solar activity (respectively $F_{10.7}=100$ and 180 ), the computed values of $A I$ for $N \mathrm{mE}$ are 0.01 for Slough-Kerguelen, 0.035 for Wallops Island-Hobart, and 0.08 for Wakkanai-Port Stanley. With the square-law loss process in the E-layer, the expected asymmetry due to Sun-Earth distance is 0.017 . We thus find no evidence of a consistent January/July asymmetry in E-layer electron density. We cannot look for evidence for any annual asymmetry in the F1-layer, because the ionosonde data are too sparse in winter to enable any valid study. Thus, as far as 
we know, only the F2-layer has a greater January/July asymmetry than would be expected from the variation of SunEarth distance.

\section{Speculative list of other possible causes}

There are other conceivable causes of the annual asymmetry in the F2-layer. Here are some:

\subsection{Any solar source other than XUV?}

This idea is entirely speculative. Unless it is of a special character that acts only on the F-layer (possibly soft electrons), which seems unlikely, the source would affect the E-layer as well. But the F-layer annual asymmetry appears to have no counterpart in the E-layer (Sect. 6.2). And why should the Sun itself have any 12-month variability?

7.2 An extraterrestrial source of ionizing radiation other than the Sun?

Galactic X-ray sources are indeed known, but their total flux is small (of order 1/1000 of solar radiation) and their ionospheric role seems insignificant except in the night E-layer (Titheridge, 2000). A sidereal source would produce opposite phases at midday and midnight, contrary to the observed F2-layer annual asymmetry. This would not necessarily be the case if the source was within or attached to the solar system, but it is hard to see what any such source could be.

7.3 A plasmaspheric or magnetospheric source above the F2-layer?

It is not clear what this might be, or whether the processes described by Richards et al. (2000) could significantly affect the F2 peak.

7.4 Hemispheric asymmetry of the geomagnetic field and the auroral ovals?

This asymmetry affects the detailed pattern of the global thermospheric circulation and its associated horizontal and vertical winds, which in turn affect thermospheric composition and hence the F2-layer electron density (e.g., Rishbeth et al., 2000a). We noted in Sect. 6.1 that the winds seem to cause a hemispheric asymmetry in the annual behaviour of the height $h m \mathrm{~F} 2$. The circulation pattern at southern solstice is not exactly a reversal of the pattern at northern solstice, and in principle this asymmetric behaviour could cause some annual asymmetry in $N m \mathrm{~F} 2$, but can it account for the consistent annual phase at different latitudes and longitudes (Table 1)? But our CTIP computations use realistic models of the geomagnetic field and auroral ovals which, unless these models are grossly in error, argues against hemispheric asymmetry being a major cause of the F2-layer January/July asymmetry.
However, we are still left with an unsolved problem of different F2-layer behaviour at March and September equinoxes.

\subsection{Other causes originating in the lower atmosphere?}

There is a possibility that the asymmetry arises from some action from below, other than tides that we discussed in Sect. 5, and might be "meteorological" in origin. This might arise from different wave regimes at the two solstices, which our computations do not include, or perhaps because of hemispheric differences in weather and climate in the lower atmosphere.

\section{Annual asymmetry: where have we reached?}

The F2-layer annual asymmetry is the global excess of F2layer ionization in December-January as compared to JuneJuly. It was first reported seventy years ago, but the only comprehensive study of ionosonde data known to us is that of Yonezawa (1971). The asymmetry can only be separated from the F2-layer seasonal (winter/summer) anomaly by combining data from northern and southern hemispheres, using stations well matched in both geographic and magnetic latitude. The details vary according to how the northern and southern data are combined, but overall the asymmetry is remarkably consistent, both at noon and at midnight.

Our analysis mainly uses monthly means of peak electron density $N m \mathrm{~F} 2$, though a limited study of the total (columnintegrated) electron content (Sect. 2.5) and the global study by Mendillo et al. (2005) show that the asymmetry exists in that too. We find no evidence that it exists in other ionospheric layers (Sect. 6). On average it increases with increasing solar activity; we have not investigated whether it is affected by geomagnetic activity. Data selection for any such study would be even more difficult than for the average conditions we assumed.

What causes the annual asymmetry? Clearly it exceeds the $7 \%$ asymmetry in ion production expected from varying Sun-Earth distance, though in principle it might be caused by some process which amplifies the effect of this varying distance. The late M. Buonsanto suggested that, at perihelion, the greater flux of solar ultraviolet causes greater dissociation of molecular oxygen than at aphelion. This affects the F2-layer loss coefficient in the right sense, but our calculations (Sect. 4.5) show that "Buonsanto's hypothesis" only increases the F2-layer asymmetry by about $1 \%$. It thus falls well short of explaining the observations, and so does any explanation we can think of based on changes of temperature, reaction rates or excited states.

Yonezawa (1971) suggested that the asymmetry might be due to some external source of ionization, other than solar photon radiation. Any strong sidereal source can be ruled out because it would produce opposite effects by day or night. It is difficult to think of any plausible source of energetic 
particles that could produce such a marked effect in the F2layer, and only the F2-layer, without obvious signatures such as airglow that would surely be detectable.

The ionosonde data suggest that, particularly at midlatitudes in the "near-pole" longitude sectors, the asymmetry is largely connected with the greater F2-layer seasonal anomaly in the North American-European sector than in the Australasian sector, as seen in the maps of Torr and Torr (1973). This cannot be the whole story because the asymmetry exists strongly at low latitudes too. But it does suggest an alternative interpretation: the asymmetry might be due to some difference between northern and southern hemispheres, rather than a difference between northern and southern solstices.

Dynamical processes are indeed important in the F2-layer, but it is hard to see how they might cause the annual asymmetry. If they do, that might be associated with annual and seasonal changes in north-south winds, as suggested by $\mathrm{Su}$ et al. (1998) in their study of the annual asymmetry at low latitudes. Such changes would be a consequence of changes in the driving force for the winds, and thus in the thermospheric heat inputs. We cannot think of any explanation involving electromagnetic drifts; such drifts greatly affect F2layer electron density in low latitudes, but they have much less effect at mid-latitudes.

We might expect the asymmetries of the geomagnetic field and the auroral zones to be a major cause of the F2-layer annual asymmetry. Our CTIP computations use an off-centred and reasonably accurate geomagnetic field model, but we do not know how sensitive the F2-layer asymmetry is to variations of the field model. As a test, we especially studied the $162^{\circ} \mathrm{W}$ meridian in the Pacific, remote from both magnetic poles so geographic and magnetic latitudes are very similar, and where we find the annual asymmetry in $N m \mathrm{~F} 2$ (and $\mathrm{O} / \mathrm{N}_{2}$ ratio) to be much the same as elsewhere. A referee suggested that the solar cycle variation of $A I$ (Fig. 3) has some resemblance to the solar cycle variation of geomagnetic activity, with peaks before and after solar maximum. Whether this could provide another clue is an interesting question for future study.

We return to the production/loss balance of the F2layer. It is known that $N m \mathrm{~F} 2$ is closely related to the atomic/molecular ratio of the ambient neutral air, which varies seasonally because of the global thermospheric circulation: the upwelling of air in the summer hemisphere decreases the atomic/molecular ratio, downwelling at winter mid-latitudes increases it. This is the basic cause of the F2layer seasonal anomaly. In principle, therefore, the annual asymmetry might be due to different patterns of upwelling and downwelling, and thus of neutral composition, in the two hemispheres. CTIP reproduces the seasonal variation of $N m$ F2 quite well (Fig. 1 of Zou et al. (2000)) but not the annual asymmetry in $N m \mathrm{~F} 2$ or $\mathrm{O} / \mathrm{N}_{2}$ ratio.

As for waves: various kinds are propagated from below into the lower thermosphere, where they are dissipated. The deposited momentum and energy may cause upwelling and downwelling which changes the atomic/molecular ratio. This may well be asymmetric between hemispheres and thus contribute to F-layer asymmetry. But when we incorporate thermospheric tides originating in the middle or lower atmosphere, the annual asymmetry is not greatly changed, partly because tides affect the thermosphere more at equinox than at solstice. So we cannot say that the asymmetry results from such tides.

Our inability to explain the January/July asymmetry with CTIP may be a limitation of the model. It appears unlikely that propagating solar diurnal and semidiurnal tides, despite their obvious effects in the lower thermosphere, play a significant role in enhancing the asymmetry. Future studies with an extended version of our model, the Coupled Middle Atmosphere and Thermosphere General Circulation Model (CMAT) (Harris et al., 2002) will include the effects of gravity waves and possibly planetary waves, and evaluate their relative importance with respect to the January/July asymmetry.

Comparing the results of different coupled models is an obvious way to proceed (though not with "non-coupled" models that assume a model neutral thermosphere and thus merely reflect any asymmetries built into those models). Some support for the idea that the annual asymmetry has to do with coupling with the lower atmosphere comes from results from the TIME-GCM coupled model, as described by Mendillo et al. (2002), though the computed asymmetry depends on the model version used. Better experimental measurements of neutral atomic/molecular ratios would clearly be helpful.

Despite our disappointment at failing to pin down the cause of the F2-layer annual asymmetry, our study has confirmed its widespread nature and given some leads. As mentioned in Sect. 5, three possibilities require investigation: non-propagating tides, which may be longitude-dependent; planetary waves; and gravity waves (other than solar tides). Any of these may deposit significant energy, varying seasonally and between hemispheres, in the lower thermosphere. We thus regard interaction with lower levels as the most likely cause of the asymmetry.

Acknowledgements. This paper originated from a suggestion by M. Buonsanto, whose death in 1999 saddened the international community of solar-terrestrial physicists. We are grateful to the ionospheric observatories whose data we have used, R. Roble for supplying TIME-GCM-CCM3 data, and R. Heelis for supplying AE-C data, which were obtained from the AE-C unified abstract data in the National Space Science Data Centre A. We also thank M. Hagan, J. Forbes and C. Fesen for useful discussions on tides; J. Titheridge, F. Rees, A. Aylward and M. Clilverd for their useful comments and suggestions; and B. Wright for help in locating old references. CTIP is a collaborative project between the Atmospheric Physics Laboratory of University College London, the School of Mathematics and Statistics of the University of Sheffield, and the NOAA Space Environment Center, Boulder, Colorado. All 
CTIP model calculations were carried out on the High Performance Service for Physics, Astronomy, Chemistry and Earth Sciences (HiPer-SPACE) Silicon Graphics Origin 2000 Supercomputer located at University College London and funded by the UK Particle Physics and Astronomy Research Council. I. C. F. Müller-Wodarg is supported by The Royal Society of London.

Topical Editor M. Pinnock thanks A. Burns and C. J. Davis for their help in evaluating this paper.

\section{References}

Akmaev, R. A. and Shved, G. M.: Modeling of the composition of the lower thermosphere taking into account of the dynamics with application to tidal variations of the OI (5577 A) airglow, J. Atmos. Terrest. Phys., 42, 705-716, 1980.

Bailey, D. K.: The geomagnetic nature of the F2 layer longitude effect, Terrest. Magn. Atmos. Elect., 53, 35-39, 1948.

Berkner, L. V. and Wells, H. W.: Non-seasonal change of F2-region ion density, Terrest. Magn. and Atmos. Elec., 43, 15-36, 1938.

Bilitza, D.: International Reference Ionosphere 2000, Radio Science 36, 261-275, 2001.

Buonsanto, M. J.: Possible effects of the changing earth-sun distance on the upper atmosphere, S. Pacific J. Nat. Sci., 8, 58-65, 1986.

Chapman, S. and Lindzen, R. S.: Atmospheric Tides. D. Reidel Publishing Co., Dordrecht, 1970.

Christensen, A. B., Paxton, L. J., Avery, S., Craven, J., Crowley, G., Humm, D. C., Kil, H., Meier, R. R., Meng, C.-I., Morrison, D., Ogorzalek, B. S., Straus, P., Strickland, D. J., Swenson, R. M., Walterscheid, R. L., Wolven, B., and Zhang, Y.: Initial observations with the Global Ultraviolet Imager (GUVI) in the NASA TIMED satellite mission, J. Geophys. Res., 108, A12, doi:10.1029/2003JA009918, 2003.

Duncan, R. A.: F-region seasonal and magnetic storm behaviour, J. Atmos. Terrest. Phys., 31, 59-70, 1969.

Fesen, C. G.: Theoretical effects of tides and auroral activity on the low latitude ionosphere, J. Atmos. Solar-Terrest. Phys., 59, 1521-1532, 1997.

Forbes, J. M. and Vial, C.: Monthly simulations of the solar semidiurnal tide in the mesosphere and lower thermosphere, J. Atmos. Terrest. Phys., 51, 649-661, 1989.

Forbes, J. M., Roble, R. G., and Fesen, C. G.: Acceleration, heating and compositional mixing of the thermosphere due to upward propagating tides, J. Geophys. Res., 98, 311-321, 1993.

Foster, J. C., Holt, J. M., Musgrove, R. G., and Evans, D. S.: Ionospheric convection associated with discrete levels of particle precipitation, Geophys. Res. Letters, 13, 656-659, 1986.

Fuller-Rowell, T. J.: The "thermospheric spoon": A mechanism for the semiannual density variation, J. Geophys. Res., 103, 39513956, 1998.

Fuller-Rowell, T. J. and Evans, D.: Height-integrated Pedersen and Hall conductivity patterns inferred from the TIROS-NOAA satellite data, J. Geophys. Res. 92, 7606-7618, 1987.

Fuller-Rowell, T. J., Rees, D., Quegan, S., Moffett, R. J., Codrescu, M. V., and Millward, G. H.: A coupled thermosphere-ionosphere model (CTIM), STEP Handbook of Ionospheric Models, edited by: Schunk, R. W., Utah State University, Logan, Utah, 217-238, 1996.
Harris, M. J., Arnold, N. F., and Aylward, A. D.: A study into the effect of the diurnal tide on the structure of the background mesosphere and thermosphere using the new coupled middle atmosphere and thermosphere (CMAT) general circulation model, Ann. Geophys., 20, 225-235, 2002, http://www.ann-geophys.net/20/225/2002/.

Hedin, A. E.: MSIS-86 thermospheric model, J. Geophys. Res., 92, 4649-4662, 1987.

Mendillo, M., Rishbeth, H., Roble, R. G., and Wroten, J.: Modelling F2-layer seasonal trends and day-to-day variability driven by coupling with the lower atmosphere, J. Atmos. Solar-Terrest. Phys. 64, 1911-1931, 2002.

Mendillo, M., Huang, C.-L., Pi, X.-Q., Rishbeth, H., and Meier, R. R.: The global asymmetry in ionospheric total content, J. Atmos. Solar-Terrest. Phys., 67, 1377-1387, 2005.

Millward, G. H., Moffett, R. J., Quegan, S., and Fuller-Rowell, T. J.: A coupled thermosphere-ionosphere-plasmasphere model (CTIP), STEP Handbook of Ionospheric Models, edited by: Schunk, R. W., Utah State University, Logan, Utah, 239-280, 1996.

Müller-Wodarg, I. C. F., Aylward, A. D., and Fuller-Rowell, T. J.: Tidal oscillations in the thermosphere: a theoretical investigation of their sources, J. Atmos. Solar-Terrest. Phys., 63, 899-914, 2001.

Rawer, K., Bilitza, D., and Ramakrishnan, S.: Goals and status of the International Reference Ionosphere, Rev. Geophys. Space Phys., 16, 177-181, 1978.

Richards, P. G., Chang, T., and Comfort, R. H.: On the causes of the annual variation in the plasmaspheric electron density, J. Atmos. Solar-Terrest. Phys., 62, 935-946, 2000.

Richmond, A. D., Blanc, M., Emery, B. A., Wand, R. H., Fejer, B. G., Woodman, R. F., Ganguly, S., Amayenc, P., Behnke, R. A., Calderon, C., and Evans, J. V.: An empirical model of quiet-day electric fields at middle and low latitudes. J. Geophys. Res, 85, 4658-4664, 1980.

Rishbeth, H.: How the thermospheric circulation affects the ionospheric F2-layer, J. Atmos. Terrest. Phys., 60, 1385-1402, 1998.

Rishbeth, H. and Müller-Wodarg, I. C. F.: Vertical circulation and thermospheric composition: a modelling study, Ann. Geophys., 17, 794-805, 1999, http://www.ann-geophys.net/17/794/1999/.

Rishbeth, H., Müller-Wodarg, I. C. F., Zou, L., Fuller-Rowell, T. J., Millward, G. H., Moffett, R. J., Idenden, D. W., and Aylward, A. D.: Annual and semiannual variations in the ionospheric F2-layer: II. Physical discussion, Ann. Geophys., 18, 945-956, 2000a.

Rishbeth, H., Sedgemore-Schulthess, K. J. F., and Ulich, Th.: Semiannual and annual variations in the height of the ionospheric F2peak, Ann. Geophys., 18, 285-299, 2000b.

Rishbeth, H., Heelis R. A., and Müller-Wodarg, I. C. F.: Variations of thermospheric composition according to AE-C data and CTIP modelling, Ann. Geophys. 22, 441-452, 2004.

Seaton, S. L. and Berkner, L. V.: Non-seasonal behavior of the Fregion, Terrest. Magn. and Atmos. Elec., 44, 313-319, 1939.

Spencer, N. W., Niemann, H. B., and Carignan, G. R.: The neutralatmosphere temperature experiment, Radio Sci., 8, 287-296, 1973.

Su, Y. Z., Bailey, G. J., and Oyama, K.-I.: Annual and seasonal variations in the low-latitude topside ionosphere, Ann. Geophys., 
16, 974-985, 1998,

http://www.ann-geophys.net/16/974/1998/.

Titheridge, J. E.: Modelling the peak of the ionospheric E-layer, J. Atmos. Solar-Terrest. Phys. 62, 93-114, 2000.

Titheridge, J. E. and Buonsanto, M. J.: Annual variations in the electron content and height of the F layer in the northern and southern hemispheres, related to neutral composition, J. Atmos. Terrest. Phys. 45, 683-696, 1983.

Torr, M. R. and Torr, D. G.: The seasonal behaviour of the F2-layer of the ionosphere, J. Atmos. Terrest. Phys. 35, 2237-2257, 1973.

Tremellen, K. W. and Cox, J. W.: Influence of wave propagation on the planning of short-wave communications, Proc. Inst. Elec. Eng., 94-IIIA, 200-219, 1947.
Yonezawa, T.: The solar-activity and latitudinal characteristics of the seasonal, non-seasonal and semi-annual variations in the peak electron densities of the F2-layer at noon and at midnight in middle and low latitudes. J. Atmos. Terrest.Phys., 33, 887-907, 1971.

Yonezawa, T. and Arima, Y.: On the seasonal and non-seasonal annual variations and the semi-annual variation in the noon and midnight electron densities of the F2 layer in middle latitudes, J. Radio Res. Labs., 6, 293-309, 1959.

Zou, L., Rishbeth, H., Müller-Wodarg, I. C. F., Aylward, A. D., Millward, G. H., Fuller-Rowell, T. J., Idenden, D. W., and Moffett, R. J.: Annual and semiannual variations in the ionospheric F2-layer: I. Modelling, Ann. Geophys., 18, 927-944, 2000, http://www.ann-geophys.net/18/927/2000/. 